NBSIR 78-1395

\title{
Performance Guidelines for A Modular Integrated Utility System
}

David J. Mitchell

Center for Building Technology National Engineering Laboratory National Bureau of Standards

Washington, D.C. 20234

November 1978

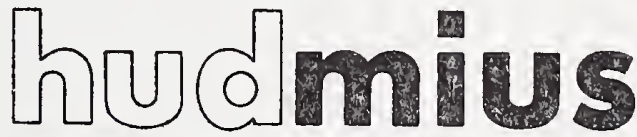
MODULAR INTEGRATED UTILITY SYSTEMS improving community utility services by supplying electricity, heating, cooling, and water/processing liquid and solid wastes/ conserving energy and natural resources/ minimizing environmental impact

Sponsored by

Division of Energy, Building Technology and Standards

- ice of Policy Development and Research : Department of Housing and Urban Development shington, D.C. 20410 


\section{PERFORMANCE GUIDELINES FOR A MODULAR INTEGRATED UTILITY SYSTEM}

David J. Mitchell

Center for Building Technology National Engineering Laboratory National Bureau of Standards

Washington, D.C. 20234

November 1978

Sponsored by

Division of Energy, Building Technology and Standards

Office of Policy Development and Research

The Department of Housing and Urban Development

Washington, D.C. 20410

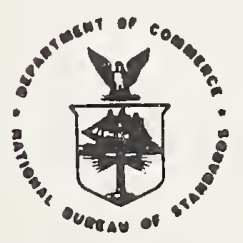

U.S. DEPARTMENT OF COMMERCE, Juanita M. Krops, Socretary

Dr. Sidney Harman, Under Secrotary

Jordan J. Baruch. Assistant Secrotary for Science and Technology

NATIONAL BUREAU OF STANDARDS. Emest Ambler, Director 
FORWARD

HUD-MIUS Program

The Deparment of Housing and Urban Development (HUD) is conducting the Modular Integrated Utility System (MIUS) Program devoted to development of the technical, economic, and institutional advantages of integrating the systems for providing all or several of the utility services for a community. The utility services include electric power, heating and cooling, potable water, liquid waste treatment, and solid waste management. The objective of the MIUS concept is to provide the desired utility services consistent with reduced use of critical natural resources, protection of the environment, and minimized cost. The program goal is to foster early implementation of the integrated utility system concept by the organization, private or public, selected by a given community to provide its utilities.

Under HUD direction, several agencies are participating in the HUD-MIUS Program. These agencies are the Department of Energy (DoE), the Department of Defense, the Environmental Protection Agency, the National Aeronautics and Space Administration, and the National Bureau of Standards (NBS).

\section{Coordinated Technical Review}

Drafts of technical documents are reviewed by the agencies participating in the HUD-MIUS Program. Comments were assembled by the DoE-ORNL Team, HUD-MIUS Project, into a Coordinated Technical Review. A draft of this publication received such a review and all comments were resolved. 
This publication was prepared as a task under the MIUS Implementation Technology Project of the NBS/HUD-MIUS Team for the HUD-MIUS Program. The leader of the MIUS Implementation Technology Project and this task is Mr. David J. Mitchell. Mr. Patrick J. Reynolds was the original task leader. The individual subsystem and system specialists who made significant contributions to the construction of the individual subsections of this publication are hereby acknowledged:

\author{
Donna L. Brown \\ Adolfo A. Camacho \\ William L. Carroll \\ John F. Halldane \\ Mark E. Kuklewicz \\ Patrick J. Reynolds \\ John R. Schaefgen \\ Walter Shipp \\ Richard J. Symuleski
}

The author wishes to recognize the invaluable review comments and contributions of the following technical specialists with respect to MIUS health and safety issues: Mr. Richard L. P. Custer, Chief of Fire Detection and Control Systems, Dr. Charles G. Culver, Disaster Research Coordinator of Office of Housing and Building Technology, Dr. Simone L. Yaniv, Technology Evaluation and Application Division, and William J. Meese, Building Environmental Division. 
ABBREVIATIONS AND ACRONYMS.........................

UNITS OF MEASURE AND S.I. CONVERSION FACTORS..............

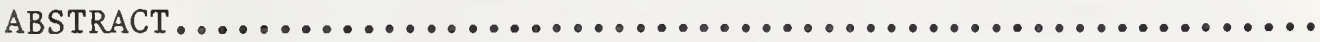

Page

vii

viii

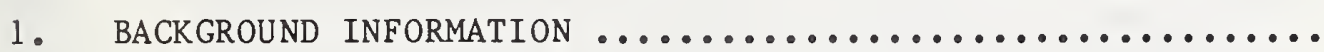

2. MIUS PERFORMANCE GUIDELINES ...................... 6

A. Electrical Supply Subsystem (ESS) .............. 6

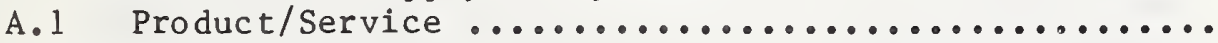

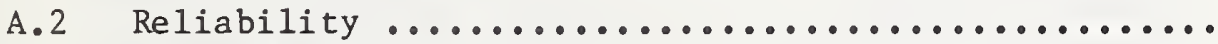

A.3 Subsystem Integration ......................

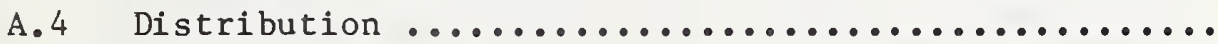

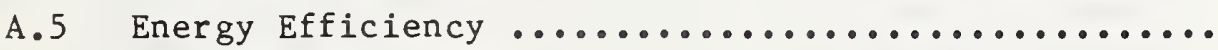

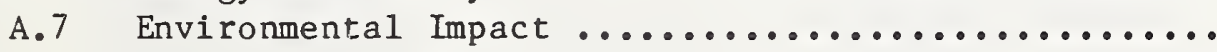

B. Thermal Subsystem (TS) .....................

B. 1 Product/Service ...........................

B.2 Reliability ............................

B.3 Subsystem Integration .....................

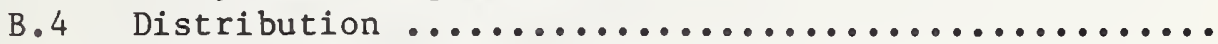

B.5 Energy Efficiency........................

B.7 Environmental Impact .....................

C. Solid Waste Management Subsystem (SWMS) ..........

C.1 Product/Service ..........................

C.2 Reliability .............................

C.3 Subsystem Integration ......................

C.4 Distribution ...........................

C.5 Energy Efficiency .......................

C.6 Controls ................................

C.7 Environmental Impact .....................

D. Wastewater Management Subsystem (WMS) ...........

D.1 Product/Service ............................

D.2 Reliability ............................

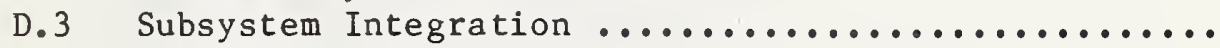

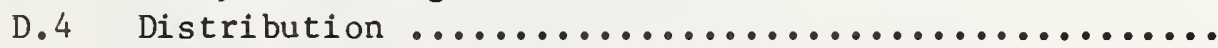

* The numbering is keyed to Table 1 Organization Matrix. For example, there is no Section A.6 - Controls because the Performance Guidelines do not address controls on a subsystem level for the ESS but on a system or MIUS leve 1 . 
E. Potable Water Management Subsystem (PWMS) .........

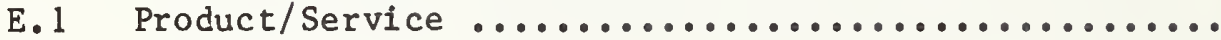

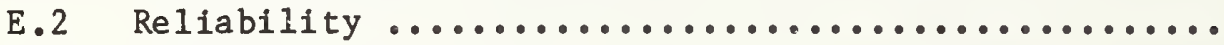

E.3 Subsystem Integration .....................

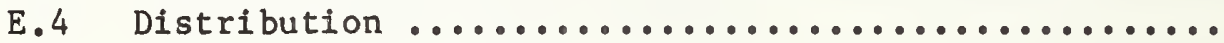

58

E. 7 Environmental Impact ......................

F. MIUS Entity .........................

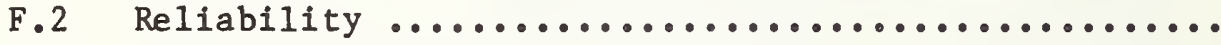

F.5 Energy Efficiency ........................

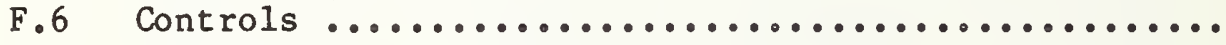

F.7 Envi ronmental Impact $\ldots \ldots \ldots \ldots \ldots \ldots \ldots \ldots \ldots \ldots \ldots$

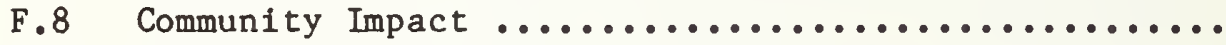

F.9 Occupational Impact .......................

F. 10 Natural Hazards 


\section{ABBREVIATIONS AND ACRONYMS}

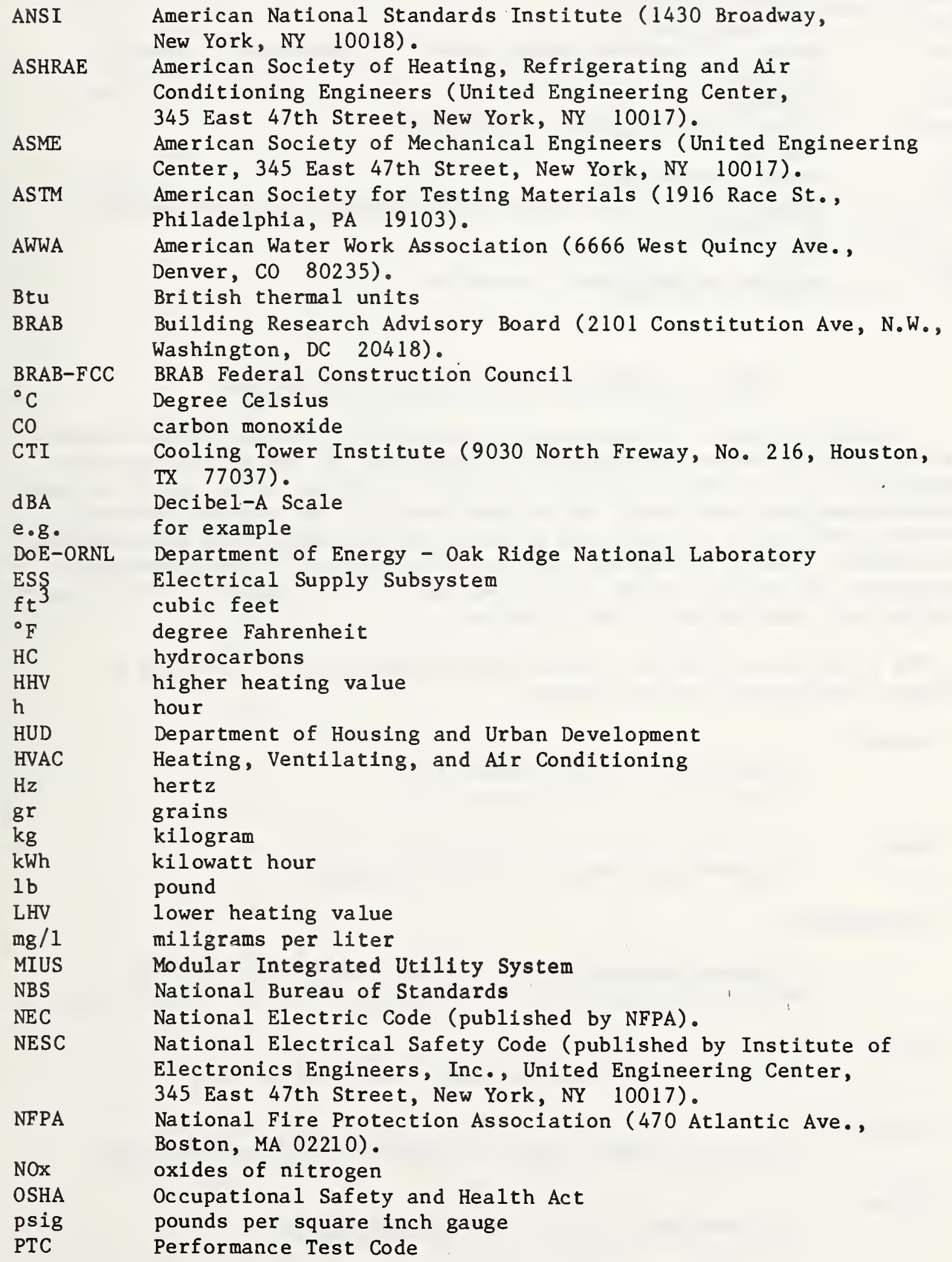




$\begin{array}{ll}\text { PWMS } & \text { Potable Water Management Subsystem } \\ \text { rdf } & \text { refuse-derived fuel } \\ \text { rms } & \text { root mean square } \\ \text { SAE } & \text { Society of Automative Engineers (400 Commonwealth Drive, } \\ & \text { Warrendale, PA 15096). } \\ \text { std } & \text { standard } \\ \text { SWMS } & \text { Solid Waste Management Subsystems } \\ \text { j } & \text { joules } \\ \text { TS } & \text { Thermal Subsystem } \\ \text { UL } & \text { Underwriter's Laboratories (333 Pfingsten Road, Northbrook, } \\ \text { V } & \text { IL } 60062 \text { ). } \\ \text { WMS } & \text { volt }\end{array}$

\section{UNITS OF MEASURE AND S.I. CONVERSION FACTORS}

In NBS Document LC 1056, revised August 1975, guidelines were established to reaffirm and strengthen the commitment of NBS to the greatest practicable use of the International System of Units (S.I.) in all of its publications and also in all of its dealings with the science and engineering communities and with the public. In this report the measurements are those of the U.S. Customary units as they appear in the referenced standards, in order that the readers may give full attention to the organization and compilation of the criteria.

The following conversion factors are appropriate for the units of measure that appear in this report:

Length -

1 1nch (in.) $=0.0254$ meter (m)

1 foot $\left(f_{0}\right)=0.3048$ meter (m)

Mass -

1 pound-mass $(1 \mathrm{bm})=.4535924$ kilogram

Temperature -

1 Degree Fahrenheit $\left({ }^{\circ} \mathrm{F}\right)=(1.8)^{-1}$ kelvin $(\mathrm{K})$ or $\left({ }^{\circ} \mathrm{K}\right)$

Temperature Fahrenheit $\left({ }^{\circ} \mathrm{F}\right)=\left(459.67+\right.$ temp. $\left.{ }^{\circ} \mathrm{F}\right) / 1.8\left({ }^{\circ} \mathrm{K}\right)$

Time -

1 hour $(h)=60$ minutes $(\min )=3600$ seconds $(s)$

Velocity -

1 foot per second $(\mathrm{fps})=0.3048$ meter per second $(\mathrm{m} / \mathrm{s})$

Force -

1 pound-force $(1 \mathrm{bf})=4.448222$ newtons $(\mathrm{N})$ 
Pressure -

1 pound-force per square inch $(\mathrm{psi})=6894.757$ pascals $(\mathrm{Pa})$

6.894747 kilopascals ( $\mathrm{kPa})$

Volume -

$$
\begin{aligned}
1 \text { U.S. liquid gallon }(\mathrm{gal}) & =0.003785412 \text { meter }{ }^{3}\left(\mathrm{~m}^{3}\right) \\
& =3.785412 \text { liters }(1)
\end{aligned}
$$

Flow Rate -

$$
\begin{aligned}
1 \text { U.S. gallon per minute }(\mathrm{gpm})= & 0.0000630902 \text { meters } 3 / \mathrm{second} \\
= & 63.0902 \text { centimeters } 3 / \mathrm{second} \\
& (\mathrm{cm} / \mathrm{s}) \\
= & 0.06309021 \mathrm{iters} / \mathrm{second}(1 / \mathrm{s})
\end{aligned}
$$


by David J. Mitchell

\section{ABSTRACT}

Performance Guidelines for a Modular Integrated Utility System (MIUS) is an aid to construct conceptual, preliminary and final designs for a specific MIUS to be built in a particular geographic location.

This document defines the suggested generic performance of a MIUS serving a residential/commerical development. Performance requirements, criteria, and evaluations identify engineering parameters and other constraints associated with electrical supply, thermal energy, solid waste management, potable water management, and wastewater management to be provided by a local, integrated source. There are also performance requirements, criteria, and evaluations for end-use considerations such as environmental impact, health, safety, and subjective acceptability. It is recognized that in view of the many possible combinations of MIUS designs, ownership, methods for implementation and local regulations, a MIUS implementor may want to omit and/or greatly simplify many of the performance requirements, criteria, and evaluations contained herein.

Keywords: Conservation; integrated utilities; performance guidelines; residential utilities; total energy, utilities.

\section{BACKGROUND INFORMATION}

\section{$\underline{\text { OB JECTIVE }}$}

This document is an aid to develop conceptual, preliminary, and final designs for a Modular Integrated Utility System and to evaluate its resultant construction and operation.

\section{SCOPE}

This document identifies the constraints associated with electrical supply, thermal energy, solid waste management, potable water supply and wastewater treatment for a residential or residential commercial development provided by a local, onsite integrated entity. This document addreses the collection and distribution of these utility services to the outer wall interface of each user building. The end-use distribution internal to a user building is not covered. The term "user building" is defined as any building or site facility served by a MIUS utility subsystem. 
The functional characteristics of a generic Modular Integrated Utility System are defined in terms of performance in contrast to a specific equipment type, make and model. Engineering parameters key to monitoring the performance of MIUS as a whole and each constituent utility are identified.

A magnitude is assigned to each engineering parameter. A method to measure the magnitude of each engineering parameter was selected from existing recognized standards or devised.

\section{PERSEPCTIVE}

A Modular Integrated Utility System can provide an acceptable quality of utility services upon demand. MIUS should maximize subsystem integration and should minimize the life-cycle cost of services rendered. The recommended functional characteristics, engineering parameters and measurement methods were developed in this light.

\section{FORMAT}

A requirement, criterion, evaluation, and commentary format is used. Each requirement is a concise statement of what the subsystem should do. Each criterion states measureable engineering parameters which would indicate whether compliance with each requirement was achieved. Each evaluation defines a standard, inspection method, review procedure, and/or test method which may be used in evaluating whether or not the subsystem or system as designed, installed and operated complies with each criterion. The commentary presents any elaboration or discussion of the requirement, criterion, or evaluation.

\section{ORGANIZATIONAL MATRIX}

Table 1 displays the topical organization of this document. The recommended performance of MIUS is defined on both a system and a subsystem level. Performance which is common to all subsystems is found on the system's level under "F. MIUS Entity". MIUS constraints are aggregated into ten categories, "1. Product or Service" through "10. Natural Hazards". The shaded areas in the organization matrix identify the information available.

\section{APPLICABLE DOCUMENTS}

It is recommended that the as-built MIUS comply with all applicable performance criteria contained herein, including the latest editions of codes, standards, and other documents cited. Beyond the specific references, use should be made of applicable codes, standards, and test methods promulgated by nationally-recognized groups such as ANSI, ASME, NFPA, ASTM, ASHRAE, and SAE. This document should not be construed to supersede local, State, and Federal codes and standards. 


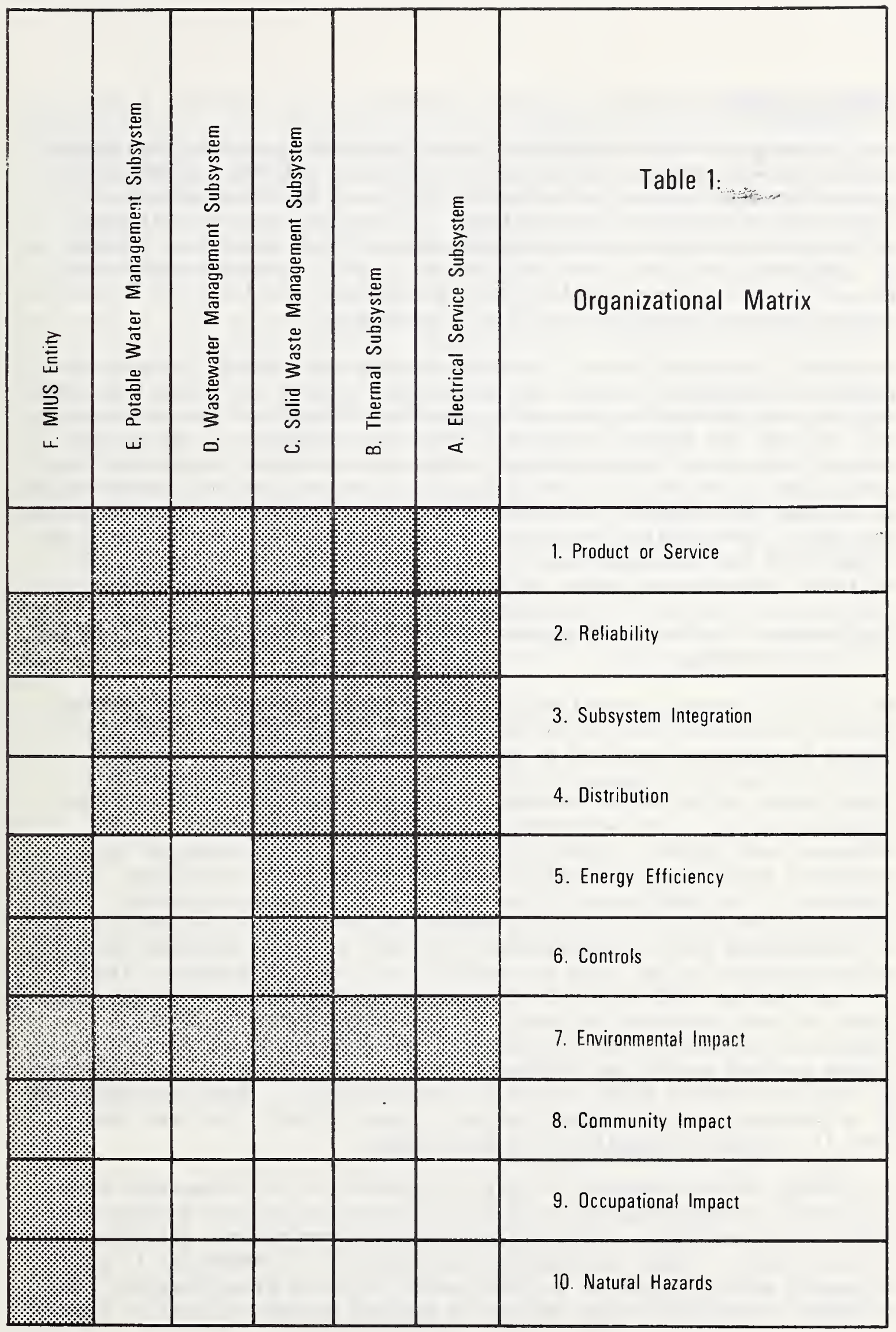


This document provides the basis for serious consideration, evaluation, and design of a MIUS. This document draws upon information developed by the HUD-MIUS program in the early 1970's. A MIUS implementor may not desire all five utility services. It is recognized that in view of the many possible combinations of MIUS designs, ownership, methods of implementation, and local regulations, a MIUS implementor may want to omit and/or greatly simplify many performance requirements, criteria and evaluations to satisfy his local constraints.

The scope, approach, format, and organization were chosen to limit the task to a practical, finite, and purposeful effort. It is believed that any limitations that may result are not significant but are recognized here so that the reader may have a clear understanding of the intent of this document. This document is a guide and is not a specification for contract. The scope of this document does not include consideration of end-use distribution of utility services internal to a user building. The use of MIUS Implies certain technical restrictions on the kinds of in-building distribution that can be used. The use of a specific inbuilding distribution places technical restrictions on MIUS. The approach is to focus the document where information is most lacking the concept of a local integrated utility and its distribution external to a user building.

The approach further restricts the scope of this document. A generic Modular Integrated Utility System is defined in performance terms utilizing parameters which can be measured. This document attempts to avoid the use of statements such as "acceptable trade practice" and "applicable public health standards" where recommended MIUS functional characteristics can be monitored via parameter measurement. It is believed such general unquantifiable statements add nothing to the technical discussion and lead to diverse unstructured individual interpretation. The magnitudes of the engineering parameters chosen reflect what has been found as a general rule to be the minimum acceptable level of performance based on experience to date. The best possible level of performance has to be based on specific cost-benefit studies tailored to a particular MIUS application. The reader should consider the magnitudes of each parameter in light of local conditions. Not enough experience exists to base the magnitude of some parameters. This may become evident due to the different levels of treatment and specificity of each recommended MIUS functional characteristic. Where the magnitude of a parameter can be defined but has a local origin, the text states that it "should be specified per site needs".

The format chosen provides a concise presentation of recommended MIUS functional characteristics and how one may verify whether an as-built MIUS is in compliance. Many performance requirements and criteria are stated briefly. Each was carefully selected. A "Commentary" is used to expand on the intent of a "Requirement" when it is purposeful. This document attempts to avoid the use of general statements such as "There 
should be a review of plans and specifications" to describe the proper "Evaluation" of each "Criterion" where nationally recognized standards and test methods exist. In most cases the "Evaluation" recommends specific methods of instrumentation, data acquisition and test. Since instrumentation and tests have limitations to their contribution to plant performance and can significantly contribute to MIUS capital, operating and maintenance costs, it is recommended that this aspect should be carefully considered and coordinated throughout a review of this document.

See Table 1. There are requirements, criteria, evaluations, and commentary for: "Product or Service"; "Reliability"; "Subsystem Integration"; "Distribution"; "Energy Efficiency"; "Controls": "Environmental Impact"; "Community Impact": "Occupational Impact and "Natural Hazards" for each utility subsystem and MIUS as a whole. There are many functional characteristics which are common to each utility service which are not of direct importance in a discussion of a Modular Integrated Utility System. In general, these are grouped in "F. MIUS Entity". There are other functional characteristics that are. These are found in the individual utility performance criteria which are labeled A, B, C, D and E. An unevenness in presentation exists due to this grouping of the performance criteria and its inherent redundancy.

This document represents the best efforts to date to address this subject and should be revised when more information and experience is gained. 
A。

\section{A.1}

A.1.1 Requirement
Electrical Supply Subsystem (ESS) - This section contains recommended generic performance requirements, criteria, evaluations, and commentary for electrical service provided by a Modular Integrated Utility System (MIUS). If electrical generation is not to be an integral part of a MIUS application, this section should be deleted or greatly revised per site needs.

If desired, the Electrical Supply Subsystem can provide electrical energy and distribute it to all user buildings. Included in this subsystem are electrical supply stations, electrical supply equipment and electrical supply lines as defined below:

electric supply equipment (supply equipment). Equipment which produces, modifies, regulates, controls, or safeguards a supply of electric energy.

electric supply lines (supply lines). Those conductors used to transmit electric energy and their necessary supporting or containing structures. Signal lines of more than 200 volts are always supply lines within the meaning of the rules, and those of less than 400 volts may be considered as supply lines, if so run and operated throughout.

electric supply station (supply station). Any bullding, room, or separate space within which electric supply equipment is located and the interior of which is accessible, as a rule, only to properly qualified persons.

NOTE: This includes generating stations and substations and generator, storage battery, and transformer rooms.

Products/Services.

General Product Description. The ESS should have sufficient capacity to supply electrical service to the user bulldings at the designated voltage, frequency, wattage and phase. 
A.1.1.1 Criterion

Evaluation

Commentary

A.1.1.2 Criterion

A.1.1.3 Criterion

Evaluation
Frequency Control. The ESS should provide electrical service at an average frequency of $60.0+0.4 \mathrm{~Hz}$. Frequency control should be maintained within a clock accuracy (National Bureau of Standards standard time, e.g., WWV) of \pm 120 seconds in a 30 day period.

Frequency should be compared against a calibrated frequency standard to determine the accumulative monthly frequency deviation.

Precise frequency control of electrical service is necessary for proper operation of customer devices such as clocks.

Phases Available. The ESS should provide both single-phase and three-phase service throughout the served area unless otherwise specified per site needs. Where three-phase service is provided, reasonable care should be exercised to insure that the load on each phase is balanced.

The voltage on each phase should be monitored.

Commentary Three-phase service may be required for motors on elevators, compressors, pumps, chillers, etc.

Delivered Voltage. The ESS should maintain at the user building interface electrical potentials of $120 \mathrm{~V}$ and $240 \mathrm{~V}$ (120 volts to ground) rms unless otherwise specified per site needs. The electrical potentials should be maintained within an average $\pm 2 \%$ of the specified values.

Evaluation The electrical potential at selected points of delivery should be monitored using instrumentation accurate to within $\pm 0.1 \%$ of the actual values.

Commentary The ESS design should minimize the number of high voltage line spikes in order to protect customer equipment.

For energy efficiency, the use of higher voltages should be encouraged where applicable (e.g. $277 \mathrm{~V}$ for commercial lighting). 
A.1.1.4 Criterion

Evaluation

A. 2

A. 2.1

A.2.1.1
Requirement

Criterion

Evaluation

Commentary
Design Peak Demand Wattage. The ESS should provide electrical service at any user building demand. The design peak demand wattage of each user building should be specified.

The probability of the subsystem to satisfy the peak electrical service demand should be evaluated by review of design calculations, vendors equipment ratings, and test results of similar equipment. Tests of the completed subsystem should be conducted under a range of test loads representing the most probable adverse circumstances to be encountered.

Reliability.

Reliability. The ESS should meet all the electrical loads of the MIUS and users with minimum interruption of service.

Interruption of Service. An interruption of service is defined as any time the electrical service does not comply with Requirement A.1.1. The aggregate number of hours per year of interruptions of electrical service to any user building should not exceed fortyeight hours. The number of interruptions of electrical service per year should not exceed five. No single interruption of service to any user building should exceed twelve hours duration.

The electrical potential, current, and frequency at the user bullding interface should be monitored. See also Evaluations: Criteria A.1.1.1 through A.1.1.3.

To produce the reliability required in Criterion A.2.1.1, the adequacy and reliability of fuel supply, required maintenance, and component reliability should be considered. Essential services include fire protection, domestic cold water supply, emergency lighting, at least one elevator installed in each tall building, sewage pumps below drain level and essential MIUS equipment.

The reliability of the ESS is in part dependent on the ESS distribution means. In order 
A.2.2 Requiremen
A.2.2.1 Criterion

Evaluation

Commentary

A. 3

A. 3.1

Requirement

A.3.1.1 Criterion

Evaluation

A.3.1.2 Criterion for the ESS distribution to be of the highest reliability for nearly all circumstances, certain designs should be given some consideration. For example, normal and emergency feeders between the MIUS and major users may be necessary; concentric rather than radial distribution loops may be used.

Load shedding of a non-essential load, such as central plant chilled water, may be an economical alternative.

Interim Supply. Interim electrical supply should be provided as a "backup" during major ESS shut-down.

ESS Back-Up Supply. The back-up supply should be compatible with all elements of the ESS in all respects so that service to user building(s) is not interrupted. The down-time of the ESS and the use of a back-up electrical supply should not in any way interrupt any essential operation of the MIUS subsystems and user buildings.

See Evaluation: Criterion A.2.1.1.

A connection to a Conventional electrical utility or to another MIUS ESS are examples of "back-up" supply.

Subsystem Integration.

ESS Integration with Other Subsystems. Certain primary and secondary products from the ESS should be available, as applicable for utilization by other MIUS subsystems.

Electrical Energy for Other MIUS Subsystems. The ESS should provide useable electrical service to other MIUS subsystems per Section A.1 - Products/Services.

The appropriate evaluations in Section A.l of this specification should apply.

Thermal Energy. The ESS should provide useable thermal energy to the THERMAL Subsystem if such utilization will result in 
net benefits in terms of resource conservation, energy efficiency, and/or financial benefit.

Evaluation See Evaluation Criterion: B.3.3.1.

Commentary The Thermal Subsystem can use ESS thermal energy for heating, cooling, and domestic hot water. The SWMS could use ESS thermal energy to dry solid waste, to keep the subsystem equipment warm and to minimize start-up fuel requirement. The WMS and PWMS could use thermal energy to increase process efficiency.

A.3.2 Requirement

A.3.2.1 Criterion

Evaluation

A.3.2.2. Criterion

Evaluation
Other Subsystem Integration with ESS. The ESS should assist the MIUS in resource conservation.

Utilization of Treated Wastewater Effluent. The ESS should utilize in its process the treated wastewater effluent from the Wastewater Management Subsystem (per Section D.) if this utilization will result in net benefits in terms of resource conservation and/or financial performance.

It should be determined whether there is a resultant net.savings to the MIUS, derived from the use of subsystem effluent, and whether the additional cost of using this effluent can be justified on a life-cycle cost basis. Data of pertinent MIUS parameters should be taken during actual performance of the installed and operating MIUS. This data should be used to calculate subsystems and MIUS water use, and life-cycle costs.

Utilization of ESS Combustible Material by SWMS. The ESS should deliver to the SWMS (per Section C.) all combustible items in a form and manner suitable for energy recovery and if such utilization results in net benefits in terms of resource conservation, energy efficiency, and/or financial performance.

Equivalent to that to investigate the MIUS potential for supplemental Thermal Energy. See Evaluation: Criteria A.3.1.2. 
Commentary

A.3.3. Requirement

A.3.3.1 Criterion

A.3.3.2 Criterion

A.3.3.3 Criterion

A. 4

A.4.1 Requirement
Examples of Combustible ESS material are boxes, crankcase oil, rages etc.

Other ESS By-Products. Solid, energy and/or fluid products of the ESS not described in Requirements A.3.1 and A.3.2 should be disposed of in an appropriate manner.

Unuseable Solid Products. The ESS should minimize solid products unuseable by other MIUS subsystems. Such unuseable solid products should be transmitted to an appropriate ESS - Solid Waste Management Subsystem interface (per Section C.) for disposal.

Evaluation See Evaluations: Criteria C.4.1.1 and C. 4.1 .2 .

Commentary Examples of unuseable solid products are worn parts and barrels.

Unuseable Aqueous Products. The ESS should minimize all aqueous products not useable by the other MIUS subsystem processes. Such unuseable aqueous products should be transmitted to an appropriate ESS - Wastewater Management Subsystem interface (per Section D.) for disposal.

Evaluation See Evaluations: Requirement D.4.1.

Unuseable Thermal Energy. The ESS should minimize all thermal energy not useable by other MIUS subsystem processes. Such thermal energy should be transmitted to an appropriate ESS Thermal Subsystem interface (per Section B.).

Evaluation See Evaluations: Requirement B.4.

Commentary During the spring and fall, modulation of the thermal energy recovered from the ESS should be considered.

Distribution.

Electrical Power Distribution. Electrical service should be effectively distributed to all MIUS user buildings and to MIUS subsystems, as required. 


\section{A.4.1.1 Criterion}

Evaluation

Commentary

A.4.1.2. Criterion

Evaluation
Electrical Codes and Standards. The electrical system shall be installed, maintained and operated in accordance with the following standards:

1. Electrical Supply Stations - Part 1 of National Electrical Safety Code (ANSI C2.1-1971)

2. Overhead Electric Supply Lines - Part 2 C2.2-1976)

3. Underground Electric Supply Lines Part 3 of National Electrical Safety Code (ANSI C.2.3-1973)

4. Grounding Methods for Electric Supply Facilities - Section 9 of National Electrical Safety Code (Section 9 of ANS I C2.2-1976)

5. Operation of Electric Supply Systems (Rules for Employees) - Part 4 of National Electrical Safety Code ANSI C2.4-1973 (Note: Where rules of the Occupational and Safety and Health Administration (OSHA) are more stringent, OSHA rules should be observed (such rules were noted in the text of NESC Part 4).

There should be review of plans and specifications and an inspection of installed equipment.

All of the above standards are published in "American National Standard National Electrical Safety Code, 1977 Edition (ANSI C2), published by the Institute of Electrical and Electronics Engineers, 345 East 47 th Street, New York, NY 10017.

Electrical Voltage Drop. The electrical voltage drop between the electrical generation elements and the user building interface at peak load should not exceed $3 \%$.

See Evaluation: Criterion A.1.1.3. 


\section{A. 5}

A.5.1 Requirement

A.5.1.1. Criterion

Evaluation

\section{Energy Efficiency.}

ESS Efficiency. The ESS should have performance characteristics that offer optimum efficiency.

Electrical Efficiency. The minimum acceptable electrical efficiency on an annual basis of the ESS should be $28 \%$ for gas or diesel generators and $17 \%$ for gas turbine-generators unless otherwise specified per site needs.

There should be a review of plans and specifications. The amount and quantity of electricity generated, its use and the fuel consumed should be monitored. The net electrical generation efficiency is defined as the sum of electrical energy metered (in $\mathrm{KWH}$ ) at the user building interface multiplied by 3413 ; divided by the sum of the higher heating values (in Btu) of all fuels used in the ESS.

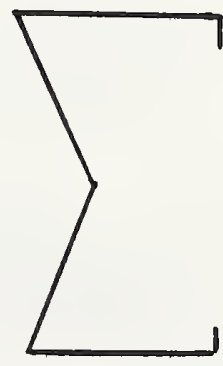

( KWH) (3413)

all points of delivery

Electrical Efficiency $=$ $\bar{\Sigma}$ (fuel units) (HHV)
all
fuels

Commentary Electrical efficiency is a key factor in achieving high overall MIUS energy efficiency.

Subsystems that use electrical energy wastefully will detract from the overall MIUS energy-use efficiency.

A.5.1.2 Criterion Gross Efficiency. The minimum acceptable gross efficiency on an annual basis for the ESS including thermal energy available to other MIUS subsystems should be $50 \%$ unless 
otherwise specified per site needs.

Evaluation There should be a review of plans and specifications. The amount and quantity of electricity generated, its fuels requirement, and use of ESS electricity and by-product thermal energy should be monitored. The ESS gross efficiency is defined as the sum of the useable energy metered at the point of delivery to the other MIUS subsystems, divided by the sum of the higher heating values (in Btu) of all fuels used in the ESS.

Gross Efficiency $=\frac{\sum \text { useable energy delivered }}{\sum \text { (fuel units) }(\mathrm{HHV})}$ a11

fuels

Commentary Care should be taken to balance the MIUS electrical and thermal energy loads. If practical, the ESS should only generate thermal energy if it can be efficiently utilized. A balanced ESS should be treated as a discretionary producer of thermal energy (like a boiler) and should not be utilized to produce thermal energy simultaneously with rejection of high-grade thermal energy by the Thermal Subsystem.

A. 7

A.7.1 Requirement

A.7.1.1 Criterion

Evaluation

Commentary
Environmental Impact.

Heat Rejection: Provisions should be made for rejection of surplus thermal energy with minimum adverse impact on the environment.

Unuseable Thermal Energy. The ESS should reject thermal energy only if its utilization and/or disposal by the Thermal Subsystem will not improve MIUS energy efficiency and/or financial performance. The ESS should minimize such reject thermal energy. The ESS heat rejection capacity should be the combined maximum surplus heat rates for all connected concurrently-operated equipment.

See Evaluation: Criterion B.3.2.1.

This criterion addresses the situation when the ESS must dispose its own unuseable therma1 energy. 

A.7.2. Requirement
Rejection of Aqueous By-products. Provi- sions should be made for disposal of aqueous products with minimum adverse impact on the envi ronment.

\section{A.7.2.1 Criterion}

Unuseable Aqueous By-products. The ESS should dispose of aqueous products only if its utilization and/or disposal by the MIUS WMS will not improve MIUS financial performance. The ESS should minimize such unuseable aqueous by-products. Where there is no sewer within a reasonable distance, suitable provision should be made for disposing ESS wastewater by a method of treatment and disposal approved by Federa1, state and local laws and regulations.

Evaluation See Evaluation: Criterion D.1.2.1. There should be a review of Federal, State and local laws and regulations.

Commentary This Criterion addresses the situation when the ESS must dispose of its own unuseable aqueous by-products.

A.7.3. Requirement

Solid Waste Disposal. Provisions should be made for solid waste disposal with minimum adverse impact on the environment.

\section{A.7.3.1 Criterion}

Evaluation

Unuseable Solid By-products. The ESS should dispose of solid by-products only if its utilization and/or disposal by the MIUS SWMS will not improve MIUS financial performance. The ESS should dispose of all unuseable solid by-products through an adequate and safe means recognized by applicable Federal, state, and local laws and regulations.

Commentary

See Evaluation: Criterion C.4.1.3

This criterion addresses the situation when the ESS must dispose of its own solid waste. 
B.

B. 1

B.1.1 Requirement

Commentary

B.1.1.1 Criterion

Evaluation

B.1.2 Requirement
Thermal Subsystem (TS) - This section contains recommended generic performance requirements, criteria, evaluations, and commentary for thermal service provided by a Modular Integrated Utility System (MIUS). If generation of chilled water and of steam or hot water for space conditioning, for domestic hot water and for other MIUS processes are not to be an integral part of a MIUS application, this section should be deleted or greatly revised per site needs.

If desired, the Thermal Subsystem can provide thermal energy and can distribute it to user buildings.

Products/Service.

Product/Service. The TS should produce, distribute and/or remove thermal energy to satisfy the requirements of all user buildings for space cooling, space heating, and domestic water heating as applicable.

This requirement on $1 y$ relates to the element of the building requirements for which the building design requires thermal fluid energy. Each building designer may determine whether building energy requirements represent a thermal energy (fluid medium) or an electrical energy demand on the MIUS.

Thermal Subsystem Service. The thermal subsystem should meet the thermal loads (heating, domestic hot water, and air conditioning) of user buildings. Adequate climatic conditions should be specified.

The probability of the subsystem to adequately service the site should be evaluated by review of design calculation, vendors equipment ratings, and test results of similar equipment. Equipment should be checked over the range of projected environmental operating conditions.

Heating. The Thermal Subsystem should provide thermal energy for domestic hot water and space heating in the user buildings. 
B.1.2.1 Criterion

Evaluation

B.1.3 Requirement

B.1.3.1 Criterion

Evaluation

B. 2

B.2.1

Requirement

B.2.1.1 Criterion

Evaluation
Domestic Hot Water and Space Heating. If thermal energy is required by a user building, it should be provided by the Thermal Subsystem. The projected maximum and minimum seasonal thermal loads of each user building to be served by the TS should be specified.

The as-built subsystem should be evaluated by operational tests in which flow rates and temperatures are monitored to determine individual building energy consumption and that of the entire site served.

Cooling. The Thermal Subsystem should provide thermal energy for space cooling in the user buildings.

Space Cooling. If thermal cooling energy is required by a user building it should be provided by the Thermal Subsystem. The projected maximum and minimum seasonal cooling load requirements of each user building to be served by the TS should be specified.

See Evaluation: Criterion B.1.2.1.

Reliability.

Reliability. The TS should meet all demands for thermal energy or its removal made by user buildings or other MIUS subsystems with a minimum interruption of service.

Space Heating. An interruption of service is defined as any time during which the space heating requirement of a user building is not met. No single interruption of service should exceed 12 hours duration. The time during which service is interrupted to a given user should total less than one week in any calendar year.

There should be: a review of plans, calculations and specifications; certification of reliability characteristics of selected components; and measurement of thermal energy medium flows, supply temperatures and return temperatures, as applicable. Actual load requriements of the MIUS and user buildings should be determined by a computer demand model verified by measured demands. 

predict equipment and service availability. The stock of spare operational components should be considered in evaluating the likely duration of unscheduled maintenance periods.

\section{B.2.1.2. Criterion}

Evaluation

Commentary

B.2.1.3 Criterion

Evaluation

Commentary

B. 3

B.3.1. Requirement

\section{B.3.1.1 Criterion}

Space Cooling. An interruption of service is defined as any time during which the space cooling requirement of a user building is not met. The total time during which service is interrupted should total less than one week per year. No single interruption of service should exceed 24 hours duration.

\section{See Evaluation: Criterion B.2.1.1.}

See Commentary: Criterion B.2.1.1. This criterion also recognizes that in order to satisfy Criterion A.2.1.1., it may be desirable to "drop" the electrical demand of TS cooling equipment for short periods of time.

Domestic Hot Water Heating. An interruption of service is defined as any time during which the domestic hot water requirement of a user building is not met. No single interruption of service should exceed 24 hours duration. The total time during which service is interrupted should total less than one week per year.

See Evaluation: Criterion B.2.1.1.

See Commentary: Criterion B.2.1.2.

Subsystem Integration.

Excess Thermal Energy. The Thermal Subsystem should accept and utilize excess thermal energy from all other MIUS subsystems.

Utilization of Thermal Energy. The Thermal Subsystem should utilize thermal energy from other MIUS subsystems (SWMS, ESS) if such a utilization results in net benefits to the MIUS in terms of energy efficiency and/or financial performance.

See Evaluation: Criterion A.3.1.2. 
Commentary

In some cases thermal storage can economically improve the utilization of recoverable "waste" energy when certain conditions such as energy need and the high cost of fossil fuel also coexist. In an ERDA ORNL Publication, ORNL-HUD-MIUS 26, it is shown that up to $22 \%$ of available heat from enginegenerators of a hypothetical MIUS model without thermal storage could be wasted during a typical year because of noncoincidence of heat availability and heat requirement. Heat availability closely matches the electrical load profile. Heat requirements are predominately determined by weather conditions.

B.3.2 Requirement

Heat Rejection. Provisions should be made for rejection of surplus thermal energy from the TS.

B.3.2.1 Criterion

Thermal Energy Rejection. The TS should reject thermal energy only if its utilization within the MIUS will not improve MIUS energy efficiency and/or financial performance and only if the $T S$ is the most efficient means of disposal. The TS should minimize unuseable TS thermal energy. TS heat rejection capacity should be the combined maximum surplus heat rates for all connected concurrently-operated subsystems.

Evaluation There should be a review of calculations, plans, and specifications. Start-up tests of the MIUS and subsystem elements should determine ability to reject maximum surplus heat. Tests in accordance with CTI Bulletin ATP-105 should be used to evaluate wet cooling tower equipment. Life-cycle costs should be analyzed to investigate utilization alternatives.

B.3.3 Requirement

Beneficial use of TS Energy. Certain primary and secondary products should be available from the TS for utilization by other MIUS subsystems.

B.3.3.1 Criterion

Thermal Energy for the MIUS Subsystems. The TS should provide useable thermal energy to all the other MIUS subsystems requiring it in the quantity and the quality necessary for the safe, reliable performance of the other subsystems. 
Evaluation

B.3.3.2 Criterion

Evaluation

B.3.3.3 Criterion

Evaluation

B.3.3.4 Criterion

Evaluation

B.3.3.5 Criterion

Evaluation
The appropriate evaluations in the energy efficiency (Section B.5) of this specification should apply to this criterion. In addition a study of a TS integrated with the appropriate other subsystem(s) should be made where there is a thermal energy flow from the TS to the other subsystem(s). This study should determine whether there is a resultant net energy savings from this energy flow and whether additional cost from implementing this energy flow can be realized in fuel and dollar savings. Data should be acquired during the actual performance of the installed and operating MIUS.

Utilization of TS Combustible Material by SWMS. The TS should deliver to the SWMS (per Section $C_{.}$) all combustible items in a form and manner suitable for energy recovery.

See Evaluation: Criterion A.3.2.2.

Unuseable Solid By-products. The TS should minimize solid by-products not useable by other MIUS subsystem processes. Such unuseable solid by-products should be transferred to the SWMS (per Section $C_{0}$ ) for disposal.

See Evaluations: Criteria C.4.1.1 and C.4.1.2.

Unuseable Aqueous By-products. The TS should minimize aqueous by-products not useable by other MIUS subsystem processes. Such unuseable aqueous by-products should be transmitted to the WMS (per Section D.) for disposal.

See Evaluations: Requirement D.4.1.

Utilization of Treated Wastewater Effluent. The TS should utilize in its process the treated wastewater effluent from the WMS (per Section D.) if this utilization will result in net benefits in terms of resource conservation, energy efficiency and/or financial performance. Criterion D.3.2.1 should apply to process water quality.

See Evaluation: Criterion A.3.2.1. 

B. 3.4
Requirement
Electrical Energy.
All electrical energy required by the TS should be of a type avail- able from and provided by the Electrical Supply Subsystem (per Section A).
B.3.4.1 Criterion
Evaluation
B. 4
B.4.1. Requirement
B.4.1.1 Criterion
TS Load. The electrical energy requirements of the TS should be included in the electri- cal load profile used to size the Electrical Supply Subsystem (per Criterion A.3.1.1). Section A.l should apply to voltage, fre- quency, wattage and phase available.
See Evaluation: Criterion A.3.1.1.
Distribution.
Heating and Cooling. The Thermal Subsystem should efficiently deliver required thermal energy to user building(s) for their cooling and heating demands.
Energy Transfer - Parameters. For all loads, the energy-related parameters of the thermal energy medium should be maintained within the design limits. These energy related parameters should be specified per site needs.

Evaluation

Commentary

B.4.1.2 Criterion
There should be a review of plans, calculations, and specifications. Thermal energy medium supply temperature, return temperature and flow should be monitored as appropriate.

Energy-transfer-related parameters refer to characteristics of the medium utilized to distribute heating and cooling to user buildings. Examples of such parameters are: media (steam, low pressure hot water), velocity, volumetric flow rate, and form (two-plpe, four-pipe).

Simultaneous Provision of Service. Space cooling, domestic hot water, and/or space heating should be provided simultaneously to meet the seasonal requirements of user buildings unless otherwise specified per site needs.

Evaluation See Evaluation: Criterion B.4.1.1. 
Commentary

B. 5

B.5.1 Requirement

B.5.1.1 Criterion

Evaluation

Commentary

B.5.1.2 Criterion

Evaluation
It is desirable to have simultaneous heating, cooling, and domestic hot water services available to user buildings. However, many central HVAC systems provide only one form of space conditioning and domestic hot water to building occupants. The implications of availability of both heating and cooling and the required use of the relatively more expensive three-pipe/four-pipe distribution can best be decided by the MIUS implementor.

Energy Efficiency.

Thermal Efficiency. The TS should make available to the user buildings thermal energy to meet the space cooling, space heating, dehumidification, and domestic hot water heating requirements by the most efficient means.

Thermal Losses. Heating and cooling energy should be distributed to user building(s), such that thermal losses from all the lines in the distribution system should be limited to not more than $5 \%$ of the energy available to the user building(s).

See Evaluation: Criterion B.4.1.1.

The selection and installation of fluidcontaining conduits should consider applicable procedures and criteria described in the District Heating Handbook, International District Heating Association, 1969; in the BRAB-FCC Reports; Underground Heat Distribution Systems (30R-64), Evaluation of Components for Underground Heat Distribution Systems (No. 39-65), or any BRAB report which might supersede them; and the ASHRAE Handbook, with respect to expansion and contraction of pipes, to damage from water and corrosion, for insulation requirements, and to mechanical protection of the conduits from surface loads or shifting earth.

Thermal Efficiency. The efficiency of the Thermal Subsystem on an annual basis, should be specified per site needs.

TS thermal efficiency of the design and as-built system should be determined. TS 
efficiency is defined as the sum of the useful thermal energy delivered (heating, cooling, domestic hot water) divided by the fue 1 input.

TS Efficiency $=\frac{\text { Useful Energy from TS }}{\text { Thermal Potential of Input Fuel }}$

1. Useful Energy from MIUS:

Useful Energy from MIUS $=h+c$

a.) Heat: "h" is the energy decrement (Btu/Year) of the thermal fluid (hot water) determined at the MIUS plant boundary multiplied by a correction for distribution losses $\left(1-D_{L}\right)$

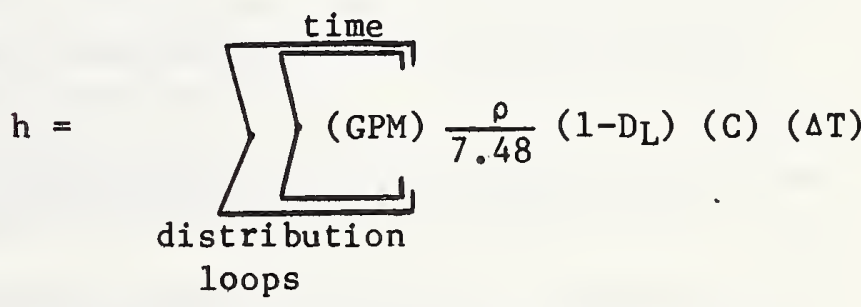

$$
\begin{aligned}
& \text { where GPM = thermal fluid low rate } \\
& \text { (gal/min) } \\
& \rho=\text { thermal fluid density } \\
& \left(1 \mathrm{~b} / \mathrm{ft}^{3}\right) \\
& D_{L}=\text { distribution loss factor } \\
& \text { (correction (\%) factor to } \\
& \text { point of delivery) } \\
& C=\text { thermal fluid heat capacity } \\
& \text { (Btu/1b/ }{ }^{\circ} \mathrm{F} \text { ) } \\
& \Delta \mathrm{T}=\text { difference between the } \\
& \text { thermal fluid supply and } \\
& \text { return temperatures }\left({ }^{\circ} \mathrm{F}\right) \\
& 7.48=\text { gallon/cubic foot }
\end{aligned}
$$

b.) Cooling: "c" is the annual cooling energy (Btu/year) removed from distribution fluid system (chilled water) determined at the plant boundary in Btu/year.

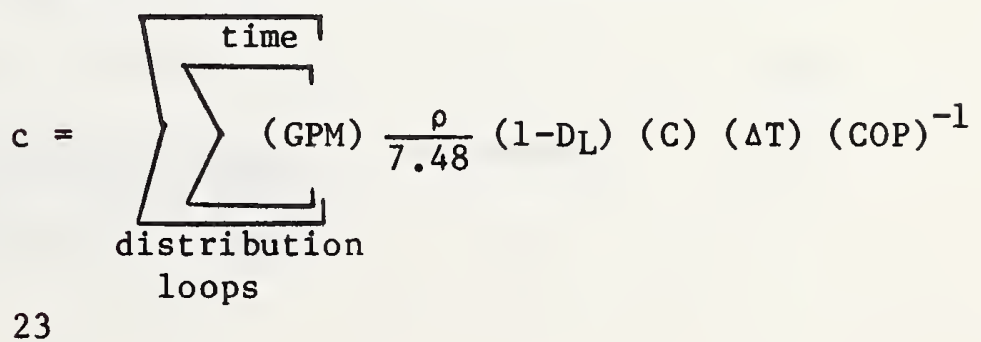




$$
\begin{aligned}
\text { where } \mathrm{GPM}= & \text { thermal fluid flow rate } \\
& (\text { gal/min) } \\
\mathrm{\rho}= & \text { thermal fluid density } \\
& \left(1 \mathrm{~b} / \mathrm{ft}^{3}\right) \\
\mathrm{D}_{\mathrm{L}}= & \text { distribution loss factor } \\
& (\text { correction }(\%) \text { factor to } \\
& \text { point of removal) } \\
\mathrm{C}= & \text { thermal fluid heat capacity } \\
& \left(\text { Btu/1b/ }{ }^{\circ} \mathrm{F}\right) \\
\Delta \mathrm{T}= & \text { difference between the } \\
& \text { thermal fluid ( } \mathrm{F}) \text { return } \\
& \text { and supply temperatures } \\
7.48= & \text { gallon/cubic foot } \\
\mathrm{COP}= & \text { Coefficient of Performance }
\end{aligned}
$$

2. Thermal Potential of Input Fuel

Thermal Input Potential = e+ftuh (Btu)

a.) Electricity: "e" is the annual sum of electricity metered at the point of use by TS and user buildings (for heating, cooling and domestic hot water via thermal distribution) multiplied by 3413 .

$$
\begin{aligned}
e= & (k W h \text { to } \mathrm{TS})+(\mathrm{kWh} \text { to user building })) \\
& \times 3413 \mathrm{Btu} / \mathrm{kWh}
\end{aligned}
$$

b.) Fuel Input: " $f$ " is the fuel input used in user buildings or supplementary boilers times HHV. The energy equivalent would be

$$
\begin{aligned}
\mathrm{f}= & \text { (Annual units of fuel supplied) } \mathrm{x} \\
& \text { (Higher Heat Value) }
\end{aligned}
$$

c.) Useable Heat: "uh" is the useable heat available from the SWMS and the ESS

Commentary Hot water is utilized as an example in the evaluation to demonstrate how compliance with the criterion is investigated. This should not be understood to suggest that only hot water is a suitable thermal distribution medium.

\section{B. 7}

B.7.1 Requirement
Environmental Impact.

Rejection of Aqueous By-Products. Provisions should be made for the disposal of aqueous by-products. 


\begin{tabular}{|c|c|c|}
\hline \multirow[t]{3}{*}{ B. 7.1 .1} & Criterion & $\begin{array}{l}\text { Unuseable Aqueous By-Products. The TS } \\
\text { should dispose of aqueous by-products only } \\
\text { if utilization and/or disposal by the MIUS } \\
\text { WMS will not improve MIUS financial perfor- } \\
\text { mance. The TS should minimize such unuseable } \\
\text { aqueous by-products. Where there is no } \\
\text { sewer within a reasonable distance, suitable } \\
\text { provisions should be made for disposing TS } \\
\text { wastewater by a method of treatment and } \\
\text { disposal approved by Federal, State and } \\
\text { local laws and regulations. }\end{array}$ \\
\hline & Evaluation & $\begin{array}{l}\text { See Evaluation: Criterion D.1.2.1. There } \\
\text { should be a review of Federal, State, and } \\
\text { local laws and regulations. }\end{array}$ \\
\hline & Commentary & $\begin{array}{l}\text { This criterion addresses the situation when } \\
\text { the TS must dispose of its own unuseable } \\
\text { aqueous by-products. }\end{array}$ \\
\hline B. 7.2 & Requirement & $\begin{array}{l}\text { Solid Waste Disposal } \\
\text { made for the disposal of solid waste. }\end{array}$ \\
\hline \multirow[t]{3}{*}{ B.7.2.1 } & Criterion & $\begin{array}{l}\text { Unuseable Solid By-products. The TS should } \\
\text { dispose of solid by-products only if its } \\
\text { utilization and/or disposal by the MIUS } \\
\text { SWMS will not improve MIUS financial per- } \\
\text { formance. The TS should minimize such } \\
\text { unuseable solid by-products. The TS should } \\
\text { dispose of all unuseable solid by-products } \\
\text { through an adequate and safe means recognized } \\
\text { by applicable Federal, State, and local laws } \\
\text { and regulations. }\end{array}$ \\
\hline & Eva luation & See Evaluation: Criterion C.4.1.3. \\
\hline & Commentary & $\begin{array}{l}\text { This criterion' addresses the situation when } \\
\text { the TS must dispose of it own unuseable } \\
\text { solid by-products. }\end{array}$ \\
\hline
\end{tabular}


This section contains recommended generic performance requirements, criteria, evaluations and commentary for solid waste management provided by a Modular Integrated Utility System. If solid waste processing (e.g., incineration with heat recovery) is not to be an integral part of a MIUS application, this section should be deleted or greatly revised per site needs.

If desired, the Solid Waste Management Subsystem can provide the systematic control of collection, storage, transport, separation, processing, recycling, recovery and disposal of refuse.

Commentary Green spaces, parking lots, and streets are considered "other facilities" in the definition of "user building".

C.1

C.1.1 Requirement

C.1.1.1 Criterion
Product/Service.

Processing. The SWMS should process refuse discarded at user buildings.

Material to be Processed. The refuse to be processed by the SWMS should be specified per site needs.

Evaluation There should be an investigation of the solid waste stream at specified input points utilizing concensus standards for: definitions and terms relating to solid waste management; a practical, statistically sound method of field sampling; sample handling and transportation; laboratory analysis procedures; and reporting formats.

The user of Section C should specify:

- (For each individual site building served) its location (e.g., Bannister Apartments Building 非1), general construction (e.g., low-rise, mid-rise) and the identification of the individual occupancies served (e.g., bowling alley, 1 bedroom apartment); and

- (For each occupancy served) the occupancy load (e.g., square feet of floor space, sleeping rooms, classrooms), the occupancy 
Commentary

C.1.1.2 Criterion

Evaluation

Commentary refuse classification (e.g., Type " 0 ", Type 1), the occupancy schedule (e.g., 9:00 am to 5:00 pm, 5 days per week, year-round residence), the refuse fractions to be processed (e.g., combustibles, a11 but food waste, bulky waste), the refuse fractions to be source separated, and the refuse fractions to be directly disposed of.

"PROCESSING" is any method, system, or treatment designed to change the physical form or chemical content of refuse. "SOLID WASTES" refers to the useless, unwanted, or discarded materials resulting from society's normal activities. The physical state of wastes may change in conveyance or treatment. It does include semi-solids such as pastes, slurries and sludges which cannot be treated in conventional wastewater treatment plants. For some purposes the point of origin is an Important factor. Refer to Table III.C.1.

Normally not all refuse will or can be processed by the SWMS. For example, bulky wastes processing at a MIUS site is normally prohibitively expensive.

There is no concensus method to investigate the solld waste stream and the technical performance of solid waste management systems at this writing. However, there are standing committees such as ASTM E38, ANSI Z228, and ASME PTC 33 that are presently working to construct such standards.

Refuse Weight Reduction. The SWMS should process refuse defined by $C .1 .1 .1$, to reduce it to at least $50 \%$ percent of its original dry weight on an annual average basis.

There should be a review of MIUS SWMS plans and specifications. Serious consideration should be given to: certification of component performance; inspection for compllance; field and/or laboratory tests; and analysis of the refuse waste system.

Refuse collected but not processed in accordance with C.1.1.1 is not counted against 
Refuse

(Solid Waste)

Composition

Source

Wastes from the preparation, cooking and serving of food.

Garbage

Market refuse, waste from the handling,

storage, and sale of produce and meat.

\begin{tabular}{|c|c|c|c|}
\hline \multirow[b]{2}{*}{ Rubbish } & $\begin{array}{l}\text { Combustible } \\
\text { (primarily } \\
\text { organic) }\end{array}$ & $\begin{array}{l}\text { Paper, cardboard, cartons. } \\
\text { Wood, boxes, excelsior. } \\
\text { Plastics. } \\
\text { Rags, cloth, bedding. } \\
\text { Leather, rubber. } \\
\text { Leaves, yard trimmings. }\end{array}$ & \multirow{2}{*}{$\begin{array}{l}\text { Households, } \\
\text { institutions, } \\
\text { and commercial } \\
\text { concerns such } \\
\text { as hotels, } \\
\text { stores, } \\
\text { restaurants, } \\
\text { markets, etc. }\end{array}$} \\
\hline & $\begin{array}{c}\text { Noncombustible } \\
\text { (primarily } \\
\text { inorganic) }\end{array}$ & $\begin{array}{l}\text { Metals, tin cans, metal } \\
\text { foils. } \\
\text { Stones, bricks, ceramics, } \\
\text { Crockery, dirt. } \\
\text { Glass, bottles. } \\
\text { Other minerals. }\end{array}$ & \\
\hline Ashe8 & $\begin{array}{l}\text { Residue from } \\
\text { for heating }\end{array}$ & $\begin{array}{l}\text { ires used for cooking and } \\
\text { ildings, cinders. }\end{array}$ & - \\
\hline
\end{tabular}

Large auto parts, tires.

Stoves, refigerators, other large appliances.

Bulky Wastes Furniture, large crates.

Trees, branches, palm fronds, stumps, flotage.

Street sweepings, dirt.

Leaves.

Street Refuse Catch-basin dirt.

Contents of litter receptacles.

St reets, sidewa lks,

Dead Animals

Small animals: cats, dogs, poultry, etc. alleys,

Large anima 18: horses, cows, etc. vacant lots, etc.

\begin{tabular}{lll}
\hline $\begin{array}{l}\text { Abandoned } \\
\text { vehicles }\end{array}$ & Automobiles, trucks. & \\
\hline $\begin{array}{l}\text { Construction \& } \\
\text { Wemolition } \\
\text { Wastes }\end{array}$ & $\begin{array}{l}\text { Lumber, roofing, and sheathing scraps. } \\
\text { Rubble, broken concrete, plaster, etc. } \\
\text { Conduit, pipe, wire, insulation, etc. }\end{array}$ & Factories, \\
\hline $\begin{array}{l}\text { Industrial } \\
\text { refuse }\end{array}$ & $\begin{array}{l}\text { Solid wastes resulting from industrial } \\
\text { processes and manufacturing operations, } \\
\text { such as food processing wastes, boiler } \\
\text { house cinders, wood, plastic, and metal } \\
\text { scraps and shavings, etc. }\end{array}$ & power \\
\hline
\end{tabular}




\section{C.1.1.5 Criterion}

Evaluation

Commentary

C. 2

C.2.1 Requirement

C.2.1.1 Criterion of the as-built SWMS. Some fugitive dust is likely to be emitted from processing equipment. This can be controlled by proper equipment design and/or ventilation systems with some form of dust collection. Liquids can also flow from processing equipment. These also can be controlled by catch basins and transported to the Wastewater Management Subsystem, WMS.

There are no data which documents 11tter generation in its various forms and correlates such generation to health and safety. To quantify this performance characteristic of refuse processing, the concept of measuring litter with respect to its percent weight of as-received refuse "charge" was developed.

SWMS Refuse Storage. MIUS should store refuse at user buildings and the MIUS itself without unsanitary and unsightly conditions. Adequate protection should be provided against unsanitary conditions, against the propagation and 11 fe support of vermin and rodents, and against objectionable odors due to the presence of stored refuse.

See Evaluation: Criterion C.1.1.2.

There are no adequate available data with respect to objectionable odors, at which level propagation and 11 fe support of vermin or what magnitude and engineering units which constitute an unsanitary conditon in an onsite RDF processing facility. Although these should be quantifiable engineering units, this was not possible at this writing.

If refuse is stored for more than 24 hours, provisions such as venting, closed contalners, deodorizers and disinfectants should be considered.

$\operatorname{Re} 11 \mathrm{abi11ty.}$

Mechanical (Operational) Avallability. The SWMS should provide user bullding(s) with dependable refuse disposal service.

On-time Service. SWMS equipment should yield a minimum of 85 percent service availability 
Eva luation

Commentary

C.2.2. Requirement

C.2.2.1 Criterion

Evaluation

Comentary over a one (1) year period, reserving 15 percent downtime allocated for maintenance and repairs. The duration of a single downtime required for major maintenance and repalrs shall not exceed 10 calendar days.

See Evaluation: Criterion C.1.1.2.

"ON-TIME SERVICE" or "MECHANICAL AVAILABILITY" means uninterrupted service based either on continuous or cyclic operation depending on the system design. "DOWNTIME" means a shutdown requiring an alternate means of solid waste disposal. Idle time, which can be used for minor or preventive maintenance and replacement of parts and components subject to normal wear and tear, should not be considered as downtime.

In most instances, the capability to utilize offsite hauling/disposal is more cost-. effective than redundant capability. The decision whether to have redundancy or to utilize offsite service will depend upon the costs of offsite hauling/disposal, of SWMS labor, and of SWMS auxiliary fuel and the flexibility and economics of waste heat recovery.

Interim Solid Waste Service. Interim solid waste disposal service should be provided as "back-up" service during major SWMS shutdown.

SWMS Back-up Service. The back-up service should be compatible with all elements of the SWMS in all respects such that solid waste disposal service to the user building(s) is not interrupted. The down-time of the SWMS and the use of a backup service should not in any way interrupt the essential operation of other MIUS subsystems.

See Evaluation: Criterion C.1.1.2.

Alternate methods of equivalent service, such as storage or a demand service contract with outside refuse haulers should be available as an integral part of site design and operation to provide the user building(s) with solid waste collection service in the event 
C. 3

C.3.1 Requirement

C.3.1.1 Criterion

Evaluation

C.3.1.2 Criterion of outages and failures of all or part of the SWMS. Where alternate means of disposal, such as landfill, are not available, it might be necessary to include a spare process line to insure uninterrupted service.

Subsystem Integration.

Integration. The SWMS should operate as an integral part of MIUS.

Integration of SWMS with other MIUS Subsystems. Before disposa1, the SWMS should process refuse which results in a costbenefit (e.g., reduced consumption of fuel, improved thermal efficiency) to the MIUS. Subsection C.1 should apply for processing, handling and storage of other MIUS subsystems refuse. Subsection C. 2 should apply to equipment selection.

See Evaluation: Criterion C.1.1.2

Energy Impact. Where the SWMS handles refuse through a thermal process, there should be provisions for energy recovery. The Energy Impact of such a thermal/energy recovery process should be positive. Energy Impact (EI) is defined as:

$E I=H-(E+T+F)$

where:

$\mathrm{H}=$ Energy actually used by other MIUS Subsystems (e.g., heat or cooling at user buildings). In the event of heat rejection by the Thermal Subsystem, this surplus recovered SWMS energy shall not be credited to "H".

$\mathrm{E}=$ Energy utilized to generate electrical energy consumed by SWMS (higher heating value).

$T=$ Thermal Input to SWMS. Consists of the incremental fuel consumption above that required by other MIUS subsystems. 


$$
\begin{aligned}
F= & \text { Fuel Input to SWMS (higher heating } \\
& \text { value) }
\end{aligned}
$$

Evaluation See Evaluation: Criterion C.1.1.2.

Commentary "Thermal Process" refers to processes such as incineration and pyrolysis.

C.3.1.3 Criterion Unuseable Aqueous Products. The SWMS should minimize all aqueous products not useable by another MIUS process. Such unuseable aqueous products should be transmitted to the WMS (per Section D.).

Evaluation See Evaluations: Requirement D.4.1.

C.3.1.4 Criterion Unuseable Thermal Energy. The SWMS should minimize all thermal energy not useable by another MIUS process. Such unuseable thermal energy should be transmitted to the TS (per Section B.).

Evaluation See Evaluations: Requirement B.4.

C.3.1.5 Criterion

Utilization of Treated Wastewater Effluent. The SWMS should utilize in its process the treated wastewater effluent from WMS (per Section D.) if this utilization will result in net benefits in terms of energy efficiency and/or financial performance. Criterion D.3.2.1 should apply to process water quality.

Evaluation See Evaluation: Criterion A.3.2.1.

C.3.1.6 Criterion

Useable Thermal Energy. The SWMS should utilize in its process useable thermal energy from TS (per Section D.) if this utilization will result in net benefits in terms of energy efficiency and/or financlal performance. Criterion B.4.1.1 should apply to energy transfer-related parameters.

Evaluation See Evaluation: Criterion B.3.3.1.

C.3.1.7 Criterion

SWMS Load. The electrical energy requirements of the SWMS should be included in the electrical load profile used to size the Electrical Supply Subsystem (per Criterion 
Evaluation

C. 4

C. 4.1

Requirement

C.4.1.1 Criterion

Evaluation

C.4.1.2 Criterion

Evaluation

Commentary

C.4.1.3 Criterion
A.3.1.1). Section A.1 should apply to voltage, frequency, wattage and phase available.

See Evaluation: Criterion A.3.1.1.

Distribution.

Collection, Transportation, and Disposal. by user building(s), should transport user building refuse to the MIUS SWMS processing facility, and should remove MIUS SWMS residue and unprocessed user building refuse to disposal.

Transportation of Refuse to be Processed. The SWMS should collect and transport refuse defined by $C .1 .1 .1$ and $C .3 .1 .1$ which is to be further processed to the SWMS equipment building. Criterion C.1.1.4 should apply to solid waste handling. Subsection C.2 should apply in equipment selection.

See Evaluation: Criterion C.1.1.2.

Collection and Transportation of Refuse to Disposal. The SWMS should collect and transport refuse from user buildings which is not to be further processed by the SWMS equipment building and processed refuse (residue) both defined by $C .1 .1 .1$ and $C .3 .1 .1$ to disposal. Criterion C.1.1.4 should apply to solid waste handling. Subsection C.2. should apply in equipment selection.

See Evaluation: Criterion C.1.1.2.

The scope of Criterion C.4.1.2 includes the removal from each user building (including MIUS SWMS) secondary materials to market or refuse which will not be processed by SWMS to disposal. If an offsite cartman or collection truck is utilized the perimeter of the SWMS for evaluation purposes will be at the offsite interface.

Disposal. The SWMS should dispose of all processed residue and unprocessed refuse defined by C.4.1.2 through an adequate and safe means recognized by applicable Federal, State and local laws and regulations. 
Evaluation See Evaluation: Criterion C.1.1.2. There should be a review of Federal, State and local laws and regulations.

Commentary "DISPOSAL" will generally include the dumping of unuseable residues and solid waste to a final disposal area (landfill) by an outside

- contractor or by selling of recovered "secondary" materials such as paper, glass, ferrous and non-ferrous at market.

C.5

C.5.1 Requirement

C.5.1.1 Criterion

Evaluation

Commentary

\section{C.5.1.2 Criterion}

Energy Efficiency.

Resource Conservation and Recovery. The SWMS concept and design should conserve energy and resources and shall be energy and resource recovery intensive.

Resource Recovery. The SWMS should recover secondary materials (e.g. glass, ferrous, paper) for resale to market when in accordance with the provisions of the other SWMS subsections and when such a utilization results in net benefits in terms of resource conservation, energy efficlency and/or financial performance.

See Evaluation: Criterion C.1.1.2. There should be a review of local secondary materials market.

To optimize the ratio of recovered energy utilized to auxiliary fuel consumption, it may be cost effective to source separate elther to improve the combustion/reliability characteristics of the refuse/RDF or to remove newsprint for sale during periods of low demand for recovered RDF energy.

Energy Efficiency. The SWMS should recover 50 percent of the total energy input (refuse, auxiliary fue 1 ) in such a way that 80 percent of this recovered energy is utilized by the Thermal Subsystem in support of user buildings. Subsection C.2 should apply to equipment selection. Subsection $C .3$ should apply to integration with other MIUS subsystems.

See Evaluation: Criterion C.1.1.2. 
Commentary The "total energy input" should include the as-received higher heating value of refuse, supplemental fuel (where required) and other energy forms (electricity) required for thermal processing and energy recovery. The choice to recover energy and at what energy utilization efficlency are dependent upon the rellability of refuse handling, disposal costs and the magnitude of fossil fuel/RDF energy substitution savings.

C. 6

C.6.1 Requirement

C.6.1.1 Criterion

Evaluation

Commentary

C. 7

C. 7.1

C.7.1.1 Criterion
Controls.

Automation. The SWMS should be automated to minimize manpower.

Automation. The SWMS should minimize subsystem dependence on manpowe $r$. Subsection C.2 should govern the level of automation practical.

See Evaluation: Criterion C.1.1.2.

The feasibility of MIUS-SWMS concept is contingent on a pre-engineered system for the particular application which optimizes fuel use/energy recovery/recovered energy utilization at minimum labor expense in lieu of separate auxiliary boiler operation while providing refuse collection/weight reduction.

Environmental Impact.

Heat Rejection. Provisions should be made for rejection of surplus thermal energy.

Unuseable Therma1 Energy. The SWMS should reject thermal energy only if its utilization and/or disposal by the Thermal Subsystem will not 1mprove MIUS financlal performance. The SWMS should minimize such unuseable thermal energy. The heat rejection capabillty should be the combined maximum design surplus heat rates for all concurrently SWMS operated equipment.

Evaluation See Evaluation: Criterion B.3.2.1.

Commentary This criterion addresses the situation when the SWMS must dispose of its own unuseable thermal energy. 


\begin{tabular}{|c|c|c|}
\hline c. 7.2 & Requil rement & $\begin{array}{l}\text { Rejection of Aqueous By-products. Provisions } \\
\text { should be made for the disposal of aqueous } \\
\text { products. }\end{array}$ \\
\hline \multirow[t]{3}{*}{ C. 7.2 .1} & Criterion & $\begin{array}{l}\text { Unuseable Aqueous By-products. The SWMS } \\
\text { should dispose of aqueous products if its } \\
\text { utilization and/or disposal by the MIUS } \\
\text { WMS will not improve MIUS financial perfor- } \\
\text { mance. The SWMS should minimize such unuse- } \\
\text { able aqueous products. Where there is no } \\
\text { sewer within a reasonable distance, suitable } \\
\text { provision should be made for disposing of } \\
\text { SWMS wastewater by a method of treatment } \\
\text { and disposal approved by Federal, State, } \\
\text { and local Water laws and regulations. }\end{array}$ \\
\hline & Evaluation & $\begin{array}{l}\text { See Evaluation: Criterion D.1.2.1. There } \\
\text { should be a review of Federal, State, and } \\
\text { local laws and regulations. }\end{array}$ \\
\hline & Commentary & $\begin{array}{l}\text { This addresses the situation when SWMS } \\
\text { must dispose of its own unuseable aqueous } \\
\text { by-products. }\end{array}$ \\
\hline
\end{tabular}


D.

D. 1

D.1.1 Requirement

D.1.1.1 Criterion

Evaluation
Wastewater Management Subsystem (WMS) -

This section contains recommended generic performance requirements, criteria, evaluations and commentary for wastewater management provided by a Modular Integrated Utility System (MIUS). If wastewater treatment is not to be an integral part of a MIUS application, this section should be deleted or greatly revised per site needs.

If desired, the Wastewater Management Subsystem can convey wastewater from user buildings, treat these wastewaters to a level adequate for final disposal or reuse and discharge the treated wastewater in an ecologically sound manner.

Some potential MIUS users could have serious environmental problems resulting from storm water runoff. The possibility of treating storm water in MIUS could be a significant advantage in specific communities. Due to Its site-specific nature, the scope of this generic MIUS performance specification does not include storm water collection, treatment, and disposal.

Product/Service.

Treatment Capacity. The MIUS WMS should accept for treatment the daily flow of wastewater conveyed from each user building.

Daily Maximum Flow. The WMS should be capable of adequately treating no less than the maximum total daily wastewater flow. The daily maximum total wastewater flow from user building should be specified per site needs.

A staged evaluation procedure should be considered to: review of design analysis, plans and specification; inspect the completed installation; and, in accordance with the procedures for measuring flow rate listed in ASTM Standard Designations D 1941-67, D 2034-68, and D 2458-69, test the performance of installed subsystem. 
The ASTM test methods cited above outline procedures for flow measurement using the Parshall flume, weirs, and the Venturi meter tube.

For this document, flow equalization is an integral part in the design of a wastewater treatment plant if used. The decision to use flow equalization or not is the perrogative of the design engineer. The MIUS WMS plant with or without flow equalization must adequately process the dally maximum wastewater flow.

D.1.1.2 Criterion

Peak Flow. The WMS should have adequate hydraulic capacity to accomodate the instantaneous peak flow rate consistent with D.1.1.1, D.3.1.1 and D.1.2. The peak flow generated by the MIUS users and MIUS subsystems should be specified per site needs and is defined as the mean rate during the maximum 15 minutes for any 12 month period.

Evaluation See Evaluation: Criterion D.1.1.1.

D.1.2 Requirement

Effluent Quality. The effluent from the WMS should be of acceptable quality.

D.1.2.1 Criterion

Acceptable Effluent Quality. An acceptable quality effluent should meet the Water Quality Standards and objectives for the recelving waters as established by the responsible Federal, State and local agencies and, at a minimum, should not contain the biological, chemical, and physical parameters listed in concentrations greater than the values or exceeding the ranges specified in Table D.1.2.la unless otherwise specified per site needs.

Evaluation There should be a review of the design, plans, and specifications and analyses of samples of treated wastewater. Recommended frequency of sampling, analysis, and analytical methods for parameters listed in Table D.1.2.1.a are referenced in Table D.1.2.1.b. Analyses should be conducted on a twenty-four hour composite sample consisting of six grab samples of volume proportional to flow, collected every four hours unless otherwise speclfled in Table D.1.2.1.b. Samples should 


\section{Parameters}

Biochemical Oxygen

Demand (BOD)

Suspended Solids (TSS)

$\mathrm{pH}$

Coliforms, Total

Turbidity

Arithmetic Mean of
Samples Analyzed
Over a Thirty Day
Time Period

30.

30.

$$
6.0-9.0
$$

$200 \mathrm{MPN} / 100 \mathrm{ml}$

10 FTU
Arithmetic Mean of Samples Analyzed Over a Seven Day Time Period

Concentrations in $\mathrm{mg} / 1$, unless otherwise noted.

FTU are Formazin Turbidity Units.

* The effluent for any given MIUS must meet these minimum standards which reflect best practicable technology as defined in 40 CFR 133FR, August 17, 1973. According to the Office of General Counsel at EPA, these standards will be enforced for the next five to ten years. After that time, effluent quality commensurate with best available technology will be required. 
TABLE D.1.2.1.b MONITORING REQUIREMENTS

Appropriate Test Methods

\begin{tabular}{|c|c|c|c|c|c|}
\hline Parameter & $\begin{array}{l}\text { EPA } \\
\text { Storet \# } \\
\end{array}$ & $\begin{array}{l}\text { Standard } \\
\text { Methods } \\
\text { Part \# } \\
\end{array}$ & $\begin{array}{l}\text { ASTM } \\
\text { Standard } \\
\text { Designation }\end{array}$ & $\begin{array}{l}\text { Analysis } \\
\text { Frequency } \\
\end{array}$ & $\begin{array}{l}\text { Sample } \\
\text { Type }\end{array}$ \\
\hline $\begin{array}{l}\text { Blochemical } \\
\text { Oxygen Demand (1) }\end{array}$ & 00310 & 219 & -- & Daily & $\begin{array}{l}24 \text { hour } \\
\text { composite }\end{array}$ \\
\hline Dissolved & & & & & \\
\hline Oxygen (2) & 00299 & $218 \mathrm{G}$ & - & Continuous & N/A \\
\hline Suspended Sol1ds & 00530 & $224 \mathrm{C}$ & $\begin{array}{c}\text { D } 1888-67 \\
(1974)\end{array}$ & Daily & $\begin{array}{l}24 \text { hour } \\
\text { composite }\end{array}$ \\
\hline $\mathrm{pH}$ (3) & 00400 & 221 & 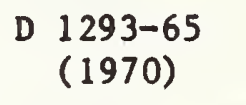 & Continuous & N/A \\
\hline Collforms, Total & - & 407,408 & -- & Da1ly & $\begin{array}{l}\text { One grab } \\
\text { sample }\end{array}$ \\
\hline Turbidity (4) & 00070 & 163,223 & D $1889-71$ & Continuous & N/A \\
\hline
\end{tabular}

If disinfection of the effluent utilizes chlorine or a chlorine contalning compound then the sampling should be conducted prior to the disinfection step.

Tests for dissolved oxygen should be conducted by the application of a dissolved oxygen probe.

Tests for $\mathrm{pH}$ should be conducted by automatic pH instrumentation which should be calibrated periodically against standard buffers of known pH per ASTM standards.

Test for turbldity should be conducted by automatic turbidimetric instrumentation calibrated periodically against a standard Formazin solution of known turbidity. 


be collected from outlet end of the effluent
discharge pipe, unless otherwise specified
in Table D.1.2.1.b.
The analytical and sampling methods referred
to in Evaluation: Criterion D.1.2.1, conform
to the latest edition of the reference methods
listed below (these are interim references
to be replaced by guidelines, when available,
promulgated pursuant to Section 304(g) of the
Federal Water Pollution Control Act Amendments
of 1972, P.L. 92-500, October 18, 1972):
"Standard Methods for the Examination of
Water and Wastewater," 14th Edition, August
1976, American Public, Health Association,
Washington, D.C. 20036.

A.S.T.M. Standards, Part 31, 1976, American Society for Testing and Materials, Philadelphia, PA 19103.

"Methods for Chemical Analysis of Water of Wastes," October 1975, U.S. Envi ronmental Protection Agency, National Environmental Research Center, Cincinnati, Ohio 45268.

D.1.3 Requirement

Fire Protection Water. To the extent practical the WMS should provide water for the MIUS fire protection systems including sprinklers, yard mains, and hose stations, unless otherwise specified per site needs or constrained by regulation.

Commentary When WMS effluent is not adequate, community fire protection water should be supplied by the PWMS.

D.1.3.1 Criterion

Water Capacity. Fire protection water capacity requirements should be defined by the fire protection system demands as specified in the appropriate National Fire Protection Standards relating to sprinklers, standpipes and water spray systems.

Capacity for community fire protection water distribution should be a defined by the Insurance Services office - 160 Water St., New York, NY 10038 (References: "Guide 
Evaluation

Commentary

D. 1.4

D.1.4.1 Criterion

Evaluation

Commentary

D.1.4.2 Criterion for Determination of Required Fire Flow," and "Grading Schedule for Municipal Fire Protection, Water Supply").

See Evaluation: Criterion D.1.1.1.

To satisfy fire protection water capacity requirements, it may be necessary to provide effluent storage facilities. If so, provisions should be made, if applicable, to prevent stored fire protection water from freezing. If the available quantity of effluent is insufficient to meet the requirements for fire protection, then it is expected that additional water (not necessarily treated to potable water quality standards) for fire protection purposes would be provided to the effluent storage facilities by the Potable Water Management Subsystem.

Irrigation Water. The WMS should make effluent available for irrigation purposes unless otherwise specified per site needs.

Water Quality. The water provided by the WMS for irrigation should meet the effluent qual1ty specified in Table D.1.3.1 if used by residents for such purposes as lawn watering and should meet the effluent qual1ty specified in Criterion D.1.2.1 if its use is restricted to trained MIUS personnel.

See Evaluation: Criterion D.1.2.1.

Irrigation water is defined as the water that is used for lawn, garden, and crop watering purposes.

Irrigation System Capac1ty. The quant1ty, the flowrate, and pressure of effluent to be supplied by the WMS as irrigation water should be spectfied as per site needs.

Evaluation See Evaluation: Criterion D.1.1.1.

Commentary See Commentary: Criterion D.1.1.1.

To satisfy irrigation water requirements, it may be necessary to provide treatment plant effluent storage facilities. If so, these 


\section{TABLE D.1.3.1 - EFFLUENT QUALITY REQUIREMENTS}

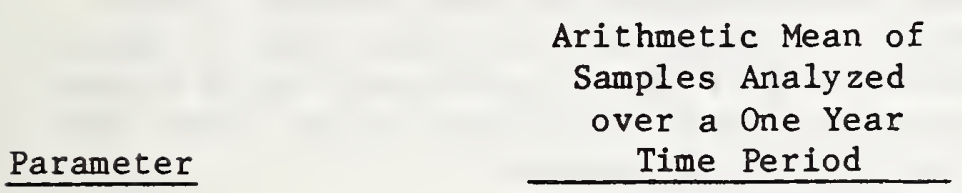

Biochemical Oxygen

Demand $\left(\mathrm{BOD}_{5}\right)$

Suspended Solids,

Total (TSS)

$\mathrm{pH}$

Coliforms, Total

Turbidity
5.

5.

$$
6.0-9.0
$$

2. $M P N / 100 \mathrm{ml}$

$10.0 \mathrm{FTU}$
Arithmetic Mean of Samples Analyzed over a Seven Day Time Period

15.

15.

$6.0-9.0$

10. $\mathrm{MPN} / 100 \mathrm{~m} 1$

$15.0 \mathrm{FTU}$

Concentrations in $\mathrm{mg} / \mathrm{l}$, unless otherwise noted.

FTU are Formazin Turbidity Units. 


\section{2 \\ D.2.1 Requirement \\ D.2.1.1 Criterion}

Evaluation

Commentary storage facilities may be combined with storage facilities that may be required for fire protection purposes. However, in the event that combined effluent storage facilities are utilized, provisions shall be made to assure that an adequate quantity of stored effluent water is available at all times for fire protection purposes.

Reliability.

Continuity of Service. The WMS should provide continuous service and treatment.

Component Reliability. No interruptions of service should be detectable by users of the subsystem. A wastewater effluent of acceptable quality shall be produced at all times. WMS reliability should as a minimum comply with the provisions of U.S. Environmental Protection Agency, Technical Bulletin EPA430-99-74-001, "Design Criteria for Mechanical, Electric, and Fluid Systems and Component Reliability," for Class 1 wastewater treatment works.

A staged evaluation program should be considered to: review design analysis, plans and specifications; analyze the power source reliability if MIUS is not to supply electrical power; inspect components and installation; field test installed components; and monitor WMS performance per parameters cited in Section $D$.

If the available electrical power supply to the WMS has reliability lower than required by this criterion, a standby powe $r$ supply sufficient to operate all vital components, during peak wastewater flow conditions together with critical lighting and ventilation should be provided. Backup components for the main wastewater treatment system should be required. Unit operations in the main wastewater treatment system should be designed such that with the largest flow capacity unit out of the service, the hydraulic capacity of the remaining units should be sufficient to handle the peak wastewater flow. There should be system flexibility to enable the wastewater flow 


\section{3}

D.3.1 Requirement

D.3.1.1 Criterion

Evaluation

Commentary

D. 3.2

Requirement

D.3.2.1 Criterion to any unit out of service to be distributed to the remaining units in service. Each component should have provisions to enable it to be isolated from the flow stream to permit maintenance and repair of the component without interruption of the system's operation.

Subsystem Integration.

MIUS Generated Wastewater. The WMS should accept treatment wastewaters for generated and discarded by the Electrical Supply, Thermal, Solid Waste Management and Potable Water Management Subsystems (per Sections A, $B, C$ and $E$, respectively).

Daily Maximum Flow. The WMS should be capable of adequately treating no less than the maximum total daily wastewater flow from MIUS subsystems which should be specified per site needs.

See Evaluation: Criterion D.1.1.1.

This criterion does not require that a separate wastewater treatment plant be provided for MIUS wastewater. If only one WMS is provided for both domestic and MIUS wastewaters, then this requirement provides that the plant be capable of processing all wastewaters received to the levels specified in Criterion: D.1.2.1.

Process Water. The WMS should supply, to the extent available, treatment plant effluent, for process water purposes to the Electrical Supply, Therma1, and Solid Waste Management Subsystems (per Sections, A, B and $C$, respectively) if such a utilization results in net benefits in terms of water conservation, energy efficiency and/or financial performance.

Process Water Quality. The quality of the treatment plant effluent to be supplied for process water purposes should be as specified in Table D.1.3.1. In addition to Table D.1.3.1 the arithmetic mean of sample analyzed for total phosphate over a seven 
day period should not exceed 4.0 miligrams per liter.

Evaluation See Evaluation: Criterion D.1.2.1.

Commentary If the quality of the effluent as specified

in D.1.3.1 is insufficient to meet the requirements of any of the subsystems utilizing WMS effluent for process applications then it is expected that the WMS will provide additional treatment and conditioning.

\section{D.3.2.2 Criterion}

Evaluation

Capacity. The WMS should provide, to the extent available, the process water requirements of the other subsystems. The treatment capacity should be the combined maximum design process water requirements for all concurrently operated subsystems.

Commentary If the quantity of effluent available from the WMS is insufficient to meet the process water requirements of any of the subsystems, it is expected that the deficient quantity of process water will be provided by the Potable Water Management System.

D.3.3 Requirement Solid Waste. Provisions should be made for the disposal of solid waste.

D.3.3.1 Criterion

Disposal. All solid wastes accumulated and generated in the WMS should be conveyed to the Solid Waste Management subsystem (per Section $C_{.}$) in a suitable form for processing and/or disposal.

Evaluation See Evaluations: Criteria C.4.1.1 and C.4.1.2.

D.3.4 Requirement Thermal Energy. All thermal energy required by the WMS should be of a type available from and provided by the Thermal Subsystem (per Section B.) if such a utilization results in net benefits to MIUS in terms of energy efficiency and/or financial performance.

D.3.4.1 Criterion WMS Load. The thermal energy requirements of the WMS should be included in the thermal 
load profiles used to size the Thermal Subsystem (per Criterion B.3.3.1). Criterion B.4.1.1 should apply to energy transferrelated parameters.

Evaluation See Evaluation: Criterion B.3.3.1.

D.3.5 Requirement

D.3.5.1 Criterion

D.3.6 Requirement

D.3.6.1 Criterion
Evaluation

Electrical Energy. All electrical energy required by the WMS should be of a type available from and provided by the Electrical Supply Subsystem.

WMS Load. The electrical energy requirements of the WMS should be included in the electrical load profile used to size the Electrical Supply Subsystem (per Criterion A.3.1.1). Section A.1 should apply to voltage, frequency, wattage and phase available.

See Evaluation: Criterion A.3.1.1.

Non-Potable Water. Additional non-potable water required by the WMS should be provided by the Potable Water Management Subsystem.

Non-Potable Water Needs. The non-potable water requirements of the WMS should be included in the capacity requirements used to size the Potable Water Management Subsystem per Criterion E.3.2.2.

Evaluation See Evaluation E.3.2.2.

Commentary Non-potable water requirements of the WMS are limited to water required as a supplemental supply to the fire protection, irrigation, and process water systems. The supplemental water for these purposes would be provided to the effluent storage facilities of WMS and does not necessarily have to be treated to potable water quality standards.

Distribution.

D. 4

D.4.1 Requirement
Wastewater Collection and Conveyance. The WMS should collect and convey all wastewaters from the MIUS user interfaces and all wastewater generated within the other MIUS subsystems to the process elements of the WMS. 
D.4.1.1 Criterion

Evaluation

D.4.1.2 Criterion

Evaluation

D.4.1.3 Criterion

Evaluation

Commentary

D. 4.2

D.4.2.1 Criterion

Evaluation

Commentary
Total Site Wastewater Flows. The total average daily flow (on an annual basis), and the minimum and peak flows from the MIUS site, each user building, and each MIUS subsystem should be specified.

See Evaluation: Criterion D.1.1.1.

User Building Wastewater Flows. The wastewater collection and conveyance facilities should be sized to adequately handle the peak and minimum flows from each user building and MIUS subsystem.

See Evaluation: Criterion D.1.1.1.

Minimum Velocity. The minimum acceptable velocity of the wastewater being conveyed should be 2.0 feet per second.

See Evaluation: Criterion D.1.1.1.

The purpose of this criterion is to insure the minimization of the deposition of suspended sollds in the WMS collection and conveyance system.

Infiltration. The infiltration of groundwater into wastewater during its conveyance should be minimized.

Allowable Infiltration. The maximum allowable infiltration of groundwater into wastewater during its conveyance should be 200 gallons per day, per mile, per inch diameter.

See Evaluation: Criterion D.1.1.1. The completed installation should be tested by one of the following methods:

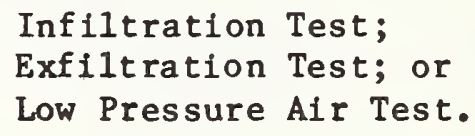

The infiltration test method is used on sewer lines where the groundwater level is sufficlently above the crown of the sewer and completely surrounds the pipeline during the period of testing. The exfiltration test method is used on sewer lines in dry areas where the groundwater head over the pipe 


\section{D.7.1.2 Criterion}

Evaluation

D.7.1.3 Criterion

Evaluation

D.7.2 Requirement

D.7.2.1 Criterion

Evaluation waters should be prepared. The National Environment Policy Act (NEPA) of 1969 and the Environmental Protection Agency (EPA) regulations entitled "Construction Grants for Waste Treatment Works" - February 11 , 1974 should be reviewed. Plans and specifications, receiving water hydrologic characteristics and soil information should be reviewed. The outfall and receiving body of water should be inspected prior to and after the start-up of the wastewater treatment plant.

Land Disposal. Effluent discharged on land should not erode, inundate or flood land in the vicinity of the disposal site.

An assessment of the environmental impact of any effluent discharge on land should be prepared. There should be a review of plans, specifications, surface and subsurface soil characteristics, topography of disposal site and adjacent lands and hydrological information. The disposal site and adjacent lands should be inspected prior to and after the start-up of the wastewater treatment plant.

WMS Thermal Discharge. Thermal discharges from the Wastewater Management Subsystem should not raise the average seasonal temperature of receiving waters within 152.4 meters of the discharge more than $2.8^{\circ} \mathrm{C}\left(5^{\circ} \mathrm{F}\right)$.

See Evaluation: Criterion F.7.1.1.

Airborne Emissions. The operation of the WMS should not cause an unacceptable degradation of the air quality as a result of emissions to the atmosphere.

Local, State and Federal Standards. The emissions to the atmosphere from the WMS should meet local, State and Federal standards.

There should be a review of plans, specifications, design and a field test of stack or vent emissions from the operating installation. Test procedures shall be as specified by the applicable regulatory agencies. 
D.7.2.2 Criterion

Evaluation

D.7.3 Requirement

D.7.3.1 Criterion

Eva luation

D.7.3.2 Criterion

Evaluation
Odor. The limits as to the average threshold odor number of gases vented from WMS should be specifled per site needs.

There should be a review of plans and specifications and a fleld test of exhaust gases from operating installation. Sample and test procedures should be in accordance with ASTM Standard Designations D1605-60 (1973) and D1391-57 (1967), respectively.

Solid Waste Disposal. Provisions should be made for the disposal of solid waste.

Unuseable Solid Products. The WMS should dispose of solid products only if its utilization and/or disposal by the MIUS SWMS wI11 not improve MIUS financial performance. The WMS should dispose of all unuseable solid products through and adequate and safe means recognized by applicable Federal, State and local laws and regulations.

See Evaluation: Criterion C.4.1.3.

Solids Concentration. In the event there is no MIUS-SWMS, all solid waste accumulated and generated in the WMS should be concentrated before disposal. The concentration percent solids by weight should be specified per site needs.

There should be a review of the design, plans, and specifications and tests of the performance of the operating subsystem. Analytical analysis should be according to Part $224 \mathrm{G}$ of, "Standard Methods for the Examination of Water and Wastewater," American Public Health Association, Washington, D.C. 20036. 
E.

E.1
E.1.1 Requirement

E.1.1.1 Criterion
Potable Water Management Subsystem (PWMS) This section contains recommended generic performance requirements, criteria, evaluations and commentary for potable water management provided by a Modular Integrated Utility System (MIUS). If potable water treatment is not to be an integral part of a MIUS application, this section should be deleted or greatly revised per site needs.

If desired, the Potable Water Management Subsystem can convey raw water from a natural source, treat the raw water to potable quality and distribute it to user buildings.

Product/Service.

Treatment Capacity. The PWMS treatment process elements should be capable of treating water for user buildings as required.

Treatment Rate and Storage. The PWMS should be capable of supplying treated water at a rate sufficient to meet all demands. These demands (MIUS, user building, total site) should be specified per site needs. The PWMS should be capable of treating, on a daily basis, no less than the maximum one day demand. Sufficient storage of treated water should be provided to meet all peak demands. The minimum storage capacity shall be equal to average daily consumption.

Evaluation There should be a review of design, plans, and specifications and tests using procedures

- for measuring flow rate of the installed subsystem such as Standard Designations D 1941-47, D 2034-68, and D 2458-69.

Commentary The ASTM test methods cited above outline procedures for flow measurement using the Parshall flume, weirs, and the Venturi meter tube.

E.1.2 Requirement Potable Water Quality. The potable water distributed to MIUS users and MIUS subsystems should be of acceptable quality.

E.1.2.1 Criterion
Acceptable Water Quality. An acceptable quality potable water should meet at a 
minimum the Drinking Water Standards as established by the responsible Federal, State or local agencles.

Evaluation There should be a review of the design, plans, and specifications and analyses of samples of treated water as per requirements of governing Drinking Water Standards. Samples should be withdrawn from the finished water outlet of the potable water treatment process.

E.2

E. 2.1

E.2.1.1 Criterion

Evaluation

Commentary

E. 3

E.3.1 Requirement
Reliability.

Continuity of Service. The PWMS should provide continuous service and treatment.

Component Reliability. No interruptions of service should be detectable by subsystem users. A potable water of acceptable quality shall be produced at all times.

A staged evaluation program should be considered to: review the design, plans, and specifications; analyze power source rel1ability; inspect components and installation; field test installed components; and monitor subsystem performance.

A standby power supply sufficient to operate al1 vital components may be required during an electrical power outage. Backup components for the main potable water treatment system should be required. Unit operations in the potable water treatment systems should be designed such that with the largest flow capacity unit out of service, the hydraulic capacity of the subsystem should be sufficient to handle the peak potable water flow. There should be subsystem flexibility to enable a malfunctioning component to be isolated from the flow stream and to permit maintenance and repair of the component without interruption of subsystem service.

Subsystem Integration.

Potable Water. The PWMS should be capable of providing potable water for consumptive uses to the electrical services, thermal 


\section{E.3.1.1 Criterion}

Evaluation

Commentary

E.3.2 Requirement

E.3.2.1 Criterion

E.3.2.2 Criterion

Evaluation

Commentary

E. 3.3

Requirement

E.3.3.1 Criterion energy, wastewater management and solid waste management subsystems.

Potable Water Capacity. The PWMS should be capable of meeting all demands for potable water by MIUS subsystems in compliance with Criterion E.1.1.1.

See Evaluation: Criterion E.1.1.1.

Potable water requirements for MIUS subsystems should be limited to water required for drinking shower, lavatory and cooking purposes (consumptive uses). See Commentary on E.3.2.1.

Non-Potable Water. The PWMS should be capable of providing the WMS all non-potable water required to meet its demands which cannot be met by the WMS effluent.

Non-Potable Water Quality. The quality of the non-potable water supplied to the WMS for distribution to MIUS subsystems should meet the requirements of Criterion D.1.4.1 and Criterion D.3.2.1.

Evaluation See Evaluations: Criterion D.1.4.1 and Criterion D.3.2.1.

If raw water does not meet the requirements of D.1.4.1, dilution with potable water or treatment of raw water to the degree required should be provided.

Non-Potable Water Capacity. Non-potable water should be supplied to the WMS by the PWMS in the quantities and at the rate required to meet all demands which cannot be met by the WMS effluent.

See Evaluation E.1.1.1.

Non-potable water should be supplied to the WMS effluent storage tank as required.

Solid Waste. Provisions should be made for the disposal of solid waste.

Disposal. All solid waste accumulated and generated in the PWMS should be conveyed to 
the solid waste management subsystem (per Section $C_{.}$) in a suitable form and in an acceptable manner for processing and/or disposal.

Evaluation See Evaluations: Criteria C.4.1.1 and C.4.1.2.

E.3.4 Requirement Thermal Energy. All thermal energy required by the PWMS should be of a type available from and provided by the thermal subsystem (per Section B.) if such a utilization results in net benefits to MIUS in terms of energy efficiency and/or financial performance.

E.3.4.1 Criterion Thermal Energy Requirements. The thermal energy requirements of the PWMS should be included in the thermal load profiles used to size the thermal subsystem (per Criterion B.3.3.1). Criterion B.4.1.1 should apply to energy transfer-related parameters.

Evaluation See Evaluation: Criterion B.3.3.1.

E.3.5 Requirement Electrical Energy. All electrical energy required by the PWMS should be of a type available from and provided by the Electrical Supply Subsystem.

E.3.5.1 Criterion

Electrical Energy Requirements. The electrical energy requirements of the PWMS should be included in the electrical load profile used to size the Electrical Supply Subsystem (per Criterion A.3.1.1). Section A.l should apply to voltage, frequency, wattage, and phase available.

Evaluation See Evaluation: Criterion A.3.3.1.

E. 4

Distribution.

E.4.1 Requirement Conveyance of Potable Water. The PWMS should be capable of conveying potable water to the interfaces of user buildings in the quantities and at the rates require in an acceptable manner. 
E.4.1.1. Criterion

E.4.1.2 Criterion

E.4.1.3 Criterion

Evaluation

E.4.1.4 Criterion

Evaluation

Commentary

E.4.2 Requirement

E.4.2.1 Criterion

Eva luation
Minimum Residual Pressure. The minimum residual pressure at all points in the conveyance system during all flow conditions should be 20 psig unless otherwise specified per site needs.

\section{Criterion E.3.3.1.}

Maximum Leakage. Leakage in the conveyance system should not exceed 20 gallons per day, per mile of pipe, per inch of nominal diameter.

There should be a leakage test in accordance with AWWA specification 0600.

Standards for Equipment. All equipment selected for the conveyance and distribution of potable and non-potable water in the PWMS should meet the minimum standards defined in the applicable specifications of the American Water Works Association.

See Evaluation: Criterion E.2.1.1.

Standards for Distribution Systems. The PWMS distribution system should conform to the requirements of the "Recommended Standards for Water Works" - Great Lakes - Upper Mississippi River Board of State Sanitary Engineers and to "Designing Community Water Systems, June 1974," New York State Department of Health.

See Evaluation: Criterion E.1.2.1.

Great Lakes Comission, 5104 lst Bldg., 3200 North Campus Blvd., Ann Arbor, Mich. 48105

Conveyance of Non-Potable Water. The PWMS should be capable of transporting non-potable water to the Wastewater Management Subsystem. The quantities and the rates required by the WMS should be specified per site needs.

Non-Potable Water to the WMS. The PWMS should be capable of transporting non-potable water to the effluent storage tank of the WMS in the quantities and at the rate required.

See Evaluation: Criterion E.1.1.1. 
E.4.2.2 Criterion

Evaluation

E.4.2.3 Criterion

Evaluation

E.4.2.4 Criterion

Evaluation

\section{E.7}

E.7.1 Requirement

E.7.1.1 Criterion

Prohibited Uses of Non-Potable Water. Only potable water should be accessible to plumbing fixtures supplying water for drinking, bathing or culinary use.

\section{National Plumbing Codes.}

Identification of Potable and Non-Potable Water. In all buildings with dual water distribution systems, one potable water and the other non-potable water, each system should be identified either by color marking or metal tags as required in ANSI A13, or other appropriate methods as may be approved by the local health authority.

ANSI Al3.1-1975, "Scheme for the Identification of Piping Systems."

Cross Connection Control. Cross connections should be prohibited except when and where, as approved by the local health authority, suitable protective devices such as the reduced pressure zone back flow preventer or equal are installed, tested and maintained to insure proper operation on a continuing basis.

AWW C 506-78, "Backflow Prevention Devices Reduced Principle and Double Check Valve Types."

Environmental Impact.

Airborne Emissions. Operation of the PWMS should not cause an unacceptable degradation of the external atmospheric environment.

Local, State and Federal Standards. The emissions to the atmosphere from the PWMS should meet local, State and Federal Standards.

Evaluation See Evaluation: Criterion D.7.2.1.

E.7.1.2 Criterion

Odor. The limits as to the average daily threshold odor number of gases vented from the PWMS should be specified per site needs.

Evaluation See Evaluation: Criterion D.7.2.2. 

E.7.2 Requirement
Solid Waste Disposal. Provisions should be made for the disposal of solid waste.
E.7.2.1 Criterion Solid Waste Concentration. In the event there is no MIUS-SWMS, all solid waste acumulated and generated in the PWMS should be concentrated to a percent solids by weight before disposal which should be specified per site needs.

Evaluation See Evaluation: Criterion D.7.3.2.

E.7.2.2 Criterion Unuseable Solid Products. The PWMS should dispose of solid products if its utilization and/or disposal by the MIUS SWMS will not improve MIUS financial performance. The PWMS should minimize such unuseable solid products. The PWMS should dispose of all unuseable solid products through an adequate and safe means recognized by applicable Federal, State and local laws and regulations.

Evaluation See Evaluation: Criterion C.4.1.3. 
F。

F.2

F.2.1 Requirement

F.2.1.1 Criterion

Evaluation

F.2.2 Requirement

F.2.2.1 Criterion
MIUS Entity*. This section contains recommended generic performance requirements, criteria, evaluations, and commentary for a Modular Integrated Utility System which has five subsystems as defined by prior Sections A, B, C, D, and E. If one or more of these prior sections required modification or were deleted, this section should be checked and revised per site needs.

Reliability.

Sustained High-Quality Service. The MIUS should provide to customers service which at a minimum is equivalent to that provided by separate conventional utilities.

MIUS Subsystem Construction. Each MIUS subsystem should be constructed of equipment which are Articles of Commerce.

Equipment should be considered an Article of Commerce if it complies with all of the following criteria. An Article of Commerce is a manufactured system, subsystem, component or element which:

1. Is commercially available;

2. Is listed with performance characteristics and ratings in commercial catalogues;

3. Has been in commercial use for at least 1 year; and

4. Can be covered by performance bond.

Life Expectancy. A reasonable, planned life expectancy should be incorporated in the MIUS concept.

Subsystem Components Life Expectancy. The MIUS should demonstrate a reasonable subsystem life expectancy. Subsystem elements should each have a life expectancy relative to its cost, to its mission, to its ease of

*Keyed to MIUS Performance Specification Organization Matrix - Table 1. 
Evaluation

Commentary

F.2.3 Requirement

F.2.3.1 Criterion

Evaluation

F.2.3.2 Criterion

Evaluation

F.2.3.3 Criterion

Evaluation

F.2.3.4 Criterion replacement and should be compatible with the life expectancies of the other MIUS subsystems.

A staged evaluation program should be considered to: review MIUS plans and specifications; certify component performance; field and/or laboratory test and inspect as-built elements.

Premature failures and excessive maintenance due to corrosion, erosion, etc., shall be minimized by proper design and selection of materials taking into consideration the costbenefit of each potential improvement.

Building systems which MIUS serves normally have a minimum useful life of 20 years.

Maintainability. Selection of the components, check points, and arrangements of components should facilitate ease of maintenance and repair.

Test Points. Test points should be provided for checking essential parameters. All test points should be readily accessible without extensive disassembly and should be identified.

See Evaluation: Criterion F.2.2.1.

Arrangement of Components. The arrangement of components should be such that replacement or adjustment of any component is possible without removal of, or damage to, adjacent components.

See Evaluation: Criterion F.2.2.1.

Standby Control System Power. Upon the event of MIUS power failure, the control system should automatically switch to a standby power source for the length of time necessary to affect an orderly shutdown and start-up.

See Evaluation: Criterion F.2.2.1.

Level of Spare Parts. Sufficient number of long lead delivery parts or other critical 
Evaluation

F. 5

F.5.1 Requirement

F.5.1.1 Criterion

Evaluation

Commentary

F.6

F.6.1 Requirement

F.6.1.1 Criterion

Evaluation

Comment ary element spare parts should be identified in relationship to the determined reliability and time to repair of such parts.

See Evaluation: Criterion F.2.2.1.

Energy Efficiency.

Resource Conservation and Recovery. The MIUS concept, design, and operation should conserve energy and other natural resources.

Resource Utilization. The MIUS should utilize a practically achievable minimum of energy and natural resources in providing user building(s) with efficient and dependable service.

See Evaluation: Criterion F.2.2.1.

MIUS should pursue conservation on the frontend, optimize process efficiencies, recover as much as practical, and process by-products for recycle/reuse. To this end, the selection of equipment should reflect consideration of the equipment's projected impact on overall MIUS energy and financial performance.

Controls.

Monitoring and Control. The control system should monitor and control the process parameters for reliable and safe operation and for optimization of MIUS performance. Its accuracy should be in accordance with the requirements of the parameter being controlled.

Monitoring and Control of Processes Parameters. Automated means for monitoring and controlling the temperatures, pressures, flows, and other critical parameters that influence the designated output conditions, proper operation condition, status, or state of the subsystem should be provided.

See Evaluation: Criterion F.2.2.1.

To assure safe reliable operation, all the parameters that effect the subsystem processes should be controlled and/or monitored. 
F.6.1.2 Criterion

Evaluation

Commentary

F.6.1.3 Criterion

Evaluation

Commentary

F.6.1.4 Criterion

Evaluation

Commentary

F.6.1.5 Criterion
Control Modes. The control system should provide for both automatic and manual operation of the subsystem equipment.

Compliance should be checked with NESC Part I, Section 17.

When the subsystem is under central supervisory control, there may be times when it will be necessary to by-pass certain scheduled central control functions.

Accuracy of the Supervisory Control System. The accuracy of the supervisory control system should be compatible within the tolerances of the parameter being controlled.

See Evaluation: Criterion F.2.2.1.

To obtain the desired parameter value, accurate supervisory control actuation is necessary to maintain the parameters under control within tolerance.

Sensor Signal Tranmission. The signal to noise ratio of sensor input to the supervisory control system should be adequate to allow reliable parameter monitoring and/or control.

Subsystem startup and acceptance tests should demonstrate that each control is receiving the specified sensor output.

Accurate control of the critical parameters requires that the accuracy of the sensor signal transmission be more than that precision tolerance of the parameter being controlled.

Sensor Tolerance. The output of the sensors should be compatible with the supevisory control/monitoring system and their accuracy should be compatible within the tolerance of the measurement of the parameter being controlled or monitored.

Evaluation The manufacture's design calculations should be reviewed for each special application sensor for comparison with the intended measurement tolerance. 
Commentary

F.6.1.6 Criterion

Evaluation

F.6.1.7 Criterion

Evaluation

F.6.1.8 Criterion

Evaluation

Commentary

F.6.1.9 Criterion

Evaluation

F.6.1.10 Criterion
See Commentary: Criterion F.6.1.4.

Sensor Deterioration. The materials and construction of all control and monitoring sensors should be such that system introduced deterioration such as corrosion should be prevented within the state-of-the-art for the intended life of the MIUS. The sensors should be selected for ease of calibration to compensate for time deterioration effects.

See Evaluation: Criterion F.2.2.1.

Tune-up. The control equipment should be designed to insure a reserve in the adjustment range for normal adjustment during maintenance. This adjustment range should be sufficient to compensate for composite variations which may develop in the associated circuitry because of changes in component values during the specified life of the equipment. The adjustment should also be capable of compensating for variations resulting from replacement of components within tolerances.

See Evaluation: Criterion F.2.2.1.

Overrides. Manually activated disconnecting devices should be provided. Such devices should be installed in a sufficient number of locations that are readily accessible to operating personnel in an emergency.

Should be in compliance with NESC, Part I, 173A - "Provisions for Disconnecting."

Manual operation is necessary for testing and maintenance of individual components.

Shutdown. The system should provide for both automatic and manual shutdown of all upstream equipments and for guards against spillage that could cause injury.

See Evaluation: Criterion F.2.2.1.

Coordination with Interfacing Subsystems. The MIUS supervisory control system should coordinate interfacing functions as required 
for reliable operation of each of the subsystems and their interfaces.

Evaluation See Evaluation: Criterion F.2.2.1.

F.6.1.11 Criterion

Energy Limiting Devices. The control system should be protected by energy limiting devices.

Evaluation See Evaluation: Criterion F.2.2.1.

F.6.2 Requirement Data Monitoring and Acquisition. A data acquisition system should be used to collect, record, and store data as needed for subsystems monitoring purposes.

F.6.2.1 Criterion

Display of Parameters. The displayed data should be self-updating in order to provide instantaneous status to the operator. The number of parameters displayed at any one time should be sufficient to provide operator with the status of the subsystem under observation.

Evaluation See Evaluation: Criterion F.2.2.1.

F.6.2.2 Criterion

Records. The control system should have the capability of recording the data required for maintenance of system performance. The storage of these data should be arranged for ease of retrieva 1.

Evaluation

See Evaluation: Criterion F.2.2.1.

Commentary Records may be required for billing, maintenance, repair, system adjustment and other purposes as determined by the operator.

F.6.2.3 Criterion

Required Number of Alarms. All critical process parameters that are being monitored and/or controlled should have an alarm function to identify deviations from their norms.

Evaluation See Evaluation: Criterion F.2.2.1.

F.6.2.4 Criterion

Alarm Modes. The control system should provide a visual and an audio alarm for each shutdown or contingency condition. Alarms should be detectable above background noise and lighting. 
Evaluation See Evaluation: Criterion F.2.2.1.

F.6.3 Requirement Control Room Functions. The monitoring and control of the process parameters should occur from a central location in the MIUS building.

F.6.3.1 Criterion Centralized Monitoring and Control. All signals should be routed to the control room for indicating, recording and/or controlling from one location. Noncontrolled measurements should be available for monitoring in this room.

Evaluation See Evaluation: Criterion F.2.2.1.

Commentary A centralized monitoring/control capability is necessary for efficient operation of the subsystem .

F.6.4 Requirement

Compatibility with Environment. The control components should be selected for compatibility with the subsystem environment.

F.6.4.1 Criterion

Operation under Environmental Conditions. The local control equipment should be capable of continuous operation under any combination of environmental conditions which may be found in the MIUS plant.

Evaluation There should be a review of the manufacturer's specifications to determine control component locations, environment, and component compatibility.

F. 7

Environmenta 1 Impact.

F.7.1 Requirement Thermal Exchange with the Environment. The thermal exchange of a MIUS with the environment should not impede nor impair the activities of the area.

F.7.1.1 Criterion

Environmental Air and Water. Change in air quality and air movement in the community should not produce hazardous climatic conditions or impede community and MIUS activities.

A11 waterborne thermal discharges from the MIUS should not raise the average seasonal temperature of receiving waters within 
152.4 meters of the discharge more than $2.8^{\circ} \mathrm{C}\left(5^{\circ} \mathrm{F}\right)$.

Evaluation

Commentary
The temperature of MIUS effluent discharges and receiving waters should be monitored.

Organisms that adapt to the higher temperature created by a MIUS could experience thermal shock if the facility closed down for maintenance, changes in operation, or emergency outages. For this reason, the rise in pond or stream water temperature is of ten limited to $2.8^{\circ} \mathrm{C}\left(5^{\circ} \mathrm{F}\right)$, although for large coal/steam/electrical power systems, $11^{\circ} \mathrm{C}\left(20^{\circ} \mathrm{F}\right)$ can be adopted if the heat sink has sufficient diffusion. Aquatic plant life can thrive with increases in water temperature, particularly if the supply streams contain phosphates such as washing detergents and agricultural fertilizers. This growth can foul stream and ponds with vegetation and may require weeding or draining procedures to eliminate it.

Local thermal inversions can occur on still, cold nights from the hot gases released from MIUS smoke stacks. This inversion traps contaminants in a blanket of ground air. When the dew point is reached, condensation could occur about particulates and cold surfaces which might form a mist hazard to traffic and ice on surfaces.

\begin{tabular}{|c|c|c|}
\hline$F .7 .2$ & Requirement & $\begin{array}{l}\text { Sewage and Stormwater. Sewage should not } \\
\text { contaminate groundwater or surface water, } \\
\text { flood, or erode the area. Rainwater should } \\
\text { not flood or erode the area, unless precip- } \\
\text { itation exceeds that of a "100-year" storm. }\end{array}$ \\
\hline F.7.2.1 & Criterion & $\begin{array}{l}\text { Topography and Surfaces. The topography and } \\
\text { surfaces about the MIUS should incorporate } \\
\text { the following: }\end{array}$ \\
\hline & & $\begin{array}{l}\text { a) Channel runoff from paved areas adjacent } \\
\text { to the MIUS; } \\
\text { b) Provide sedimentation ponds for runoff; } \\
\text { c) Provide retention areas for flood control } \\
\text { and controlled run-off; and } \\
\text { d) Provide for oil and grease interceptors } \\
\text { for vehicle and equipment areas. }\end{array}$ \\
\hline
\end{tabular}


Evaluation

Commentary

F.7.3 Requirement

F.7.3.1 Criterion
See Evaluation: Criterion F.2.2.1

Whether or not items (b) and (c) are provided separately or in conjunction with those for the development served is a local option and is not excluded by this Criterion.

Air Contaminants. The discharge of contaminants to the atmosphere from a MIUS plant should be maintained within legislated limits.

Standards and Regulations. All air contaminants from the MIUS should comply with the Federal Air Quality Standards, Environmental Protection Agency (EPA) Regulations or relevant State and local Laws, whichever is the more limiting.

\section{Internal Combustion Engines}

Internal combustion engine emissions should be equal to or less than those indicated in the table below.

Stationary Engine and Gas Turbine Emission Limits

Engine Type

$\left(1 \mathrm{~b} / 10^{6} \mathrm{Btu}\right) *$

\begin{tabular}{|c|c|c|c|}
\hline & NOx & $\mathrm{CO}$ & $\underline{\mathrm{HC}}$ \\
\hline Diesel & 3.3 & 1.2 & .0 \\
\hline Dual Fuel & 3.0 & 0.74 & 1.1 \\
\hline Natural Gas & 3.9 & 0.43 & 0.62 \\
\hline Gas Turbine & 0.34 & - & \\
\hline
\end{tabular}

* Energy content of gaseous fuels will be based on LHV. Energy content of oil fuels will be based on HHV.

Subpart D - Fossil Fuel Fired Steam Generators

a.) Particulates:

There should not be more than $0.101 \mathrm{~b} / 10^{6}$ Btu, or $43 \mathrm{~kg} / \mathrm{TJ}$ of particulate mass per unit heat input, except as relaxed by EPA regulations for large generators, if permitted by other applicable standards and regulations. 
Visible particulates should not be darker in shade than that designated as $\mathrm{Nr} 1$ on the Ringelman Scale or $20 \%$ equivalent opacity, except $2 \mathrm{~min}$. intervals in any one hour when particulate emission may be as great as $\mathrm{Nr} .2$ on the Ringelman Scale or $40 \%$ equivalent opacity.

b.) Sulfur Dioxide, $\mathrm{SO}_{2}$

There should not be more sulfur dioxide emission, mass per unit heat input, maximum $2 \mathrm{hr}$. mean, from the following fossil fuel phases.

Phase Mass/heat input, maximum $2 \mathrm{hr}$. mean

Liquid $\left(1 \mathrm{~b} / 10^{6} \mathrm{Btu}\right)$

Solid $(0.80)$ $(\mathrm{kg} / \mathrm{TJ})$

Liquid $(1.20)$

\& solid $\frac{Y(0.80)+Z(1.2)}{Y+Z} \frac{Y(345)+Z(518)}{Y+Z}$

Where $\mathrm{Y}=\%$ total heat derived from 1iquid fossil fuel

$Z=\%$ total heat derived from solid fossil fuel

c.) Nitrogen Dioxide, $\mathrm{NO}_{2}$

There should not be more nitrogen emission, mass per unit heat input, maximum 2 hr. mean, from the following fossil fuel phases.

Phase

aseous

Liquid

Solid

(not lignite)

Gaseous, Liquid,
Solid
Mass/heat input, maximum $2 \mathrm{hr}$. mean

(1 b/10 ${ }^{6} \mathrm{Btu}$ )

$(0.20)$

$(0.30)$

$(0.70)$ 
Phase

$\begin{array}{ll} & (\mathrm{kg} / \mathrm{TJ}) \\ \text { Gaseous } & (86) \\ \text { Liquid } & (130) \\ \text { Solid } & (302) \\ \text { (not lignite) } & \end{array}$
Gaseous, Liquid, Solid

Mass/heat input, maximum 2 hr. mean

$(\mathrm{kg} / \mathrm{TJ})$

(130)

(302)

$$
\begin{aligned}
& \text { Where } \mathrm{X}=\% \text { total heat derived from } \\
& \text { gaseous fossil fuel }
\end{aligned}
$$

Subpart E - Incinerators

Particulates should be less than $0.08 \mathrm{gr} / \mathrm{std}$. $\mathrm{ft}^{3}$ (maximum $2 \mathrm{hr}$. mean) corrected to $12 \%$ carbon dioxide, or when sludge from wastewater treatment is incinerated, particulate matter should not discharge at a rate in excess of $0.65 \mathrm{~g} / \mathrm{kg}$. during a $1.301 \mathrm{~b} / \mathrm{ton}$ dry sludge input.

Evaluation Test methods should be in accordance with the relevant EPA regulations on standards for Performance for new stationary sources (40 CFR 60, 36 FR 24876, Dec. 23, 1971):

\section{Subpart D - Fossil Fuel Fired Steam Generators}

Emission and Fuel Monitoring 60.45

Directs test methods and procedures for -Particulates to Methods $1,2, \underline{5}, \underline{9}$ Sulfur dioxide to Methods $1,2,3,6$ Nitrogen dioxide to Methods $1,2,3, \underline{7}$ Moisture to Method 5

Method 1 Sample and velocity traverse for stationary sources

Method 2 Determination of stack gas velocity and volumetric flow rate (Type 5 pitot tube) 
Method 3 Gas Analysis for carbon dioxide, excess air, and dry molecular weight.

Method 5 Determination of particulate emissions.

Method 6 Determination of sulfur dioxide emissions.

Method 7 Determination of nitrogen oxide emissions.

Method 9 Visual determination of the opacity of emissions.

Method 10 Determination of carbon monoxide emissions.

P.7.4 Requirement

Electromagnetic Interference. Electromagnetic radiation and induction from the electrical equipment of the MIUS should not impede electronic systems performance in the community.

F.7.4.1 Criterion

Electromagnetic Radiation and Induction. All electromagentic radiation and induction from the MIUS should be below levels that will interfere with the proper performance of adjacent electronic equipment.

Evaluation The proposed MIUS plans and specifications should be reviewed to insure that an effective electrical grounding system is installed. The services of a Professional Radio Engineer should be engaged.

F.8

Community Impact.

F.8.1 Requirement Sound in Community. Sound from the MIUS should not adversely effect the health and safety of the public in the adjacent community activities.

\section{E.8.1.1. Criterion}

Acoustics. To avoid impeding normal voice communications of nearby people $10 \mathrm{ft}$. from buildings, the A weighted sound level should always be less than $60 \mathrm{~dB}$ measured $5 \mathrm{ft}$. above ground level and at a distance of 10 ft. from a MIUS exterior wall when the community sounds are also below $60 \mathrm{~dB}$.

When outside community sounds exceed an A-weighted sound level of $60 \mathrm{~dB}$ at all times, the MIUS should not be heard, and therefore it shall generate sound pressure levels less 
than those for the adjacent activity at a distance $10 \mathrm{ft}$. from a MIUS exterior wall.

Occassional peak sounds of dumpings, backing trucks, garbage cans, etc. lasting less than 2 min. in $1 \mathrm{hr}$. intervals should not peak the A-weighted sound level of $78 \mathrm{~dB}$.

Evaluation

Comment ary

F.8.2 Requirement

F.8.2.1 Criterion

Evaluation

Commentary

F.8.3 Requirement

F.8.3.1 Criterion
The mean and peak sound pressure levels (A-weighted) should be monitored by outside measurements. Worst conditions for activities should be reviewed.

Background noise level should be at least $10 \mathrm{~dB}$ below MIUS generated noise before its measurement.

Visual Compatibility in Community. Visual appearance of a MIUS should be compatible with those of the adjacent activities and buildings .

Visual Compatibility of the MIUS. Materials should be durable for consistent aging and resistant to vandalism. MIUS activities incongruous with those of the community should be screened from view. MIUS landscaping should be consistent with community landscaping. Distribution elements of the MIUS should not impair the activities of the community .

See Evaluation: Criterion F.2.2.1.

Incongruous MIUS conditions and activities may include storage stacks of coal, garbage, or scrap metal, extensively paved areas, transformers, switch gear, walls, and fencing if not compatible with adjacent structures. Wire fences could be compatible with recreational (tennis, basketbal1) fencing.

Smells in Community. Smells from the MIUS facility should not adversely affect the adjacent community activities.

Odor Emissions. To avoid the perception of incongruous odors in the adjacent community, smell emissions should be controlled so that the component chemicals fall below threshold concentrations. 
Evaluation

F.8.4 Requirement

F.8.4.1 Criterion

F.9

F.9.1 Requirement

F.9.1.1 Criterion

Evaluation
There should be a professional review of MIUS activities, particularly storage of decaying organic materials, sludge, petroleum transfer storage, exhaust emissions. Odor control mechanisms such as filters, ducting, ventilation, off-gas collection should be reviewed. olfactory field test by an experienced professional should detect odors and trace their odor sources.

Transportation in Community. MIUS generated transportation and access should be compatible with local traffic in order that the community and MIUS activities are unimpeded.

MIUS Related Transportation. Access to and from the MIUS systems or subsystems, for the transfer of energy sources, solid waste, and materials should not impede the community or MIUS services.

MIUS related vehicles should be compatible with the community access, road systems, and solid waste collection. Wheel load on road pavements should be less than or equal to those permitted for the locality. Turning circles, and vehicle dimensions should not be hazardous to traffic, pedestrians, and property.

Evaluation See Evaluation: Criterion F.2.2.1.

Commentary Vehicle operations should avoid evening periods when the community is quiet, and peak commuter times when local traffic densities are high.

Occupational Impact.

Manpower. Qualified personnel should attend to the operational control of the MIUS to ensure an efficient maintenance of service.

Schedules, Parameters, and Procedures. Operating schedules, ranges for operating parameters, and emergency sequencing procedures should be displayed adjacent to the relevant controls and in a MIUS operation manual available at the operator's office.

See Evaluation: Criterion F.2.2.1. 

F.9.2 Requirement
Emergency Access and Egress. The MIUS design should avoid impeding or impairing both a rapid emergency egress and an emer- gency access.

F.9.2.1 Criterion

Emergency Access and Egress. Planning and maintenance of spaces should afford an unhindered passage for access. Emergency operation schedules should be summarized adjacent to the relevant controls and detailed in an operation manual. Personnel should be trained in executing emergency procedures. Egress routes should be protected from smoke and fire by self-closing doors of at least $1 / 2 \mathrm{hr}$. fire endurance and walls of at least 1 hr. fire endurance.

Evaluation See Evaluation: Criterion F.2.2.1.

F.9.2.2 Criterion

Evaluation

F.9.2.3 Criterion
Smoke Control. A smoke control system should be provided to maintain exit corridors and stairways at a positive pressure of at least 0.1 inch water column gauge with respect to the compartment on fire. The smoke control system should be automatically activated by any fire alarm device provided in Requirement F.9.3. Manual actuation of the smoke control system from central location should also be provided. All ducts penetrating rated fire partitions should be provided with dampers that will close automatically upon actuation of the fire alarm system. The smoke control system should conform to the design specifications of NEPA $90 \mathrm{~A}$ and ASHRAE guidelines.

See Evaluation: Criterion F.2.2.1.

Manual Alarm Stations. Manual alarm stations should be provided at exits from all fire compartments -- on the inside of exits through exterior walls and immediately outside exits passing through interior walls. In addition to manual stations, the alarm should be coupled to any smoke or heat sensors and suppression system alarm devices. Additional emergency notification should be provided for control system malfunction, sewage overflow and security devices. The alarm should sound throughout the MIUS premises and in a central control area. The alarm system should discriminate between 
fire and other emergency situations at the control center.

Evaluation See Evaluation: Criterion F.2.2.1.

F.9.3 Requirement $\frac{\text { Automatic Suppression Systems. Automatic }}{\text { suppression systems should be provided in }}$
all appropriate spaces in the MIUS.

F.9.3.1 Criterion Design and Installation. Automatic suppression systems should conform to the appropriate NFPA standards.

Evaluation See Evaluation: Criterion F.2.2.1.

F.9.4 Requirement Occupational Environment. All spaces and equipment, used and maintained by authorized personnel should comply with legislation affecting the occupational environments of workers.

F.9.4.1 Criterion Work Environment. All work envi ronments should comply with the (William Steiger) Occupational Safety and Health Act of 1970. Relevant portions for a MIUS include the following:

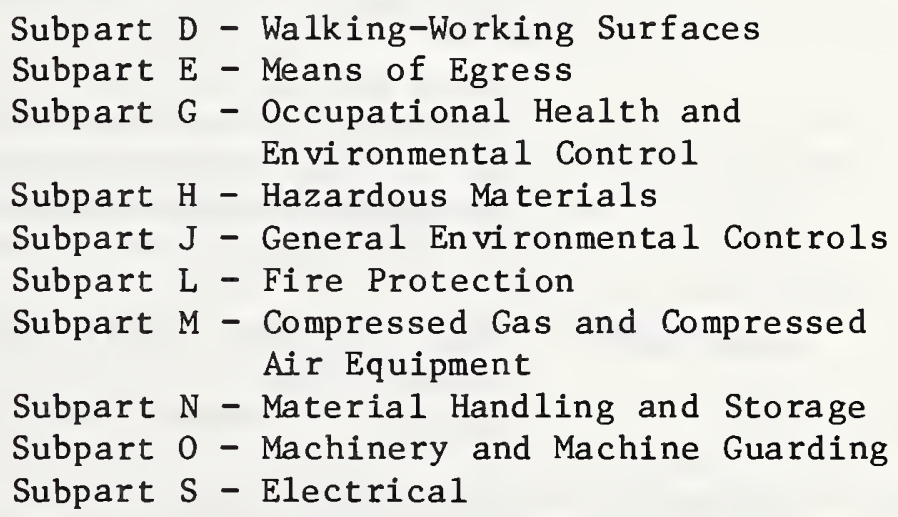

Evaluation See Evaluation: Criterion F.2.2.1.

Commentary The OSHA is a combination of performance and design specifications which may be covered by other sections. Where OSHA Criteria are lacking the current NFPA National Fire Codes should be applied.

F.9.5 Requirement Community Security. MIUS property buildings and equipment should impede unauthorized entry and vandalism in order to maintain 
F.9.5.1 Criterion

Evaluation

Commentary

F. 9.6

Requirement

F.9.6.1 Criterion

Evaluation

F.9.6.2 Criterion continuous operations and protect the community from subsequent hazards.

MIUS Security. All MIUS properties, buildings, and equipment should be secured from entry by unauthorized persons or stray animals. All MIUS property, buildings and equipment shall be constructed and controlled to withstand the vandalism that is common in the community. Communication of MIUS security breaches to operating personnel shall be facilitiated through appropriate surveillance.

See Evaluation: Criterion F.2.2.1.

In Principle all likely points of entry and storage areas should be capable of surveillance from the operating engineers' office. Good lighting and unobstructed view provide suitable deterrents. There should be no windows or doors directly accessible to the community. Children and scavenging animals should be discouraged from the storage stacks, receiving hoppers and vehicle paths. A rapid disposal of waste can minimize the problem of vermin and scavenging animals.

Entry alarms on doors and windows should be provided. Vandalism common to the community may be ascertained from police reports and interviews, school maintenance records, and the electrical power company.

Human Factors. MIUS design of the control system should take into account the requirements of the human operator.

Electrical Safety. The control system and equipment should be designed so that external metal parts are at ground potential.

See Evaluation: Criterion F.2.2.1.

Thermal Hazard. A subsystem control equipment which its normal operation exposes personnel to surface temperatures in excess of $65.6^{\circ} \mathrm{C}\left(150^{\circ} \mathrm{F}\right)$ should be appropriately guarded and marked.

Evaluation See Evaluation: Criterion F.2.2.1. 
F.9.6.3 Criterion

Evaluation

Commentary

F.10

F.10.1 Requirement

F.10.1.1 Criterion
Interlocks. The automatic operation of devices or controls which would present hazards to operators in the area should be prevented from operating through a locking control. The position of such a locking control should have a visual warning device.

See Evaluation: Criterion F.2.2.1.

The design of control system should be such as to preclude the possibility of operating personnel coming in contact with hazardous fluids, voltages, electric currents, hot surfaces, rotating machinery, or other similar hazards.

Natural Hazards.

Fire Hazard. The MIUS entity should not constitute a fire hazard.

Fire Safety Codes and Regulations. Combustible materials for energy conversion should be received, stored, distributed, and used according to local legislation, the Occupational Safety and Health Act (Subpart $H$, Hazardous Materials, and Codes affecting the individual equipment elements).

Potential origins for the ignition of flammable materials should be identified from causes both inside and outside the MIUS entity. Potential distribution for the spread should be identified for causes both inside and outside the MIUS entity.

System control of potential fire origins and distribution should be incorporated in the operation, equipment, buildings, and storage related to the MIUS. Controls should avoid the impeding or impairment of the community activities. The effectiveness of controls should meet local legislation, National Fire Protection Association codes, building codes, and codes affecting the individual equipment elements.

MIUS facilities provide a continuous service to the community and, therefore, should be fire compartmentized according to hazards, 
Evaluation

F.10.2 Requirement

F.10.2.1 Criterion

Evaluation

Commentary

F.10.3 Requirement and provided with automatic fire extinguishers control systems for facilitate a resumption of service and minimize an economic loss. The criteria for occupancy, fire zoning, types of construction, and fire resistance should meet the local building code requirements for fire safety construction.

The design should be reviewed for legislative and code compliance. The potential origins for ignition and distribution of fire should be reviewed. The facility should be inspected for compliance with F.10.1.1. Regular hazard control system tests should be undertaken including detection sensors, alarms, emergency action, and egress drill.

Flood Hazards. The equipment of a MIUS should be protected against flooding which would impair service to the community.

Flood Control to Maintain MIUS Service and Equipment. To avoid an impairment to service, corrosion of equipment, thermal cracking, silting, and insulation failure, the water level should not immerse water sensitive MIUS equipment. In predicting a natural flood level the 100 year flood plans for the site should be adopted. See U.S. Army Corps of Engineers for Regulatory Flood Datum.

The probable highest flood level should be established to determine whether continent flooding and control of flooding will affect the continuity of service.

A MIUS is likely to be at the lower point of the drainage area by virtue of the sewage flow. Flooding could occur from rising rivers, detained runoff water, hydrant overflow, sprinklers, and as a result of new construction.

Seismic Hazard. The MIUS equipment and buildings should be designed to accommodate anticipated earthquake motions at the site and earthquake induced effects such as ground rupture, land slides, or liquifaction in order to maintain operations following an earthquake. 
F.10.3.1 Criterion

Evaluation

F.10.4 Requirement

F.10.4.1 Criterion

Evaluation

F.10.5 Requirement

\section{F.10.5.1 Criterion}

Evaluation

Commentary
Seismic Hazard. To avoid structural collapse, and alignment problems associated with the translational displacements of faulting, no part of a MIUS entity should be constructed over an active geological fault. MIUS should accommodate seismic motions that are probable in the locality.

The earthquake history of the general region of the site should be documented. A review should be given of available historical records, of reports of ground shaking, damage and of other intensity information near the site. The maximum intensities (Modified Mercal1i) of ground shaking on firm ground near the site should be estimated and the earthquakes which could give severe ground shaking should be defined.

Lightning Hazard. All MIUS equipment and buildings should be protected against lightning discharge in order to maintain operation.

Lightning Hazard. Suitable precautions should be taken to protect MIUS equipment against lightning or excessive over-voltages. Lightning arresters shall be located as close as practical to the equipment they protect.

Should be in compliance with NESC, Part I, Section 19.

Wind Hazard. The MIUS equipment and buildings should accommodate local wind activity in order to maintain continuous operations.

Wind. To avoid excessive structural stress, deflections and displacements, the MIUS should accommodate wind pressure that is probable in the area. Criteria for wind loading and deflections should be in accordance with the local building code.

See Evaluation: Criterion F.2.2.1.

Control of wind blown materials is also essential. 
F.10.6 Requirement Precipitation Hazard. The effects of precipitation in the form of rain, hail or snow should not impede the MIUS service to the community nor impair the MIUS facility.

F.10.6.1 Criterion Precipitation. Rain should not interrupt the MIUS services nor impair the MIUS buildings and equipment. Runoff should be collected and conveyed from the MIUS.

Hail should not interrupt the MIUS services nor impair the MIUS buildings and equipment. All MIUS construction should withstand the impact and accumulations of hail that area common to the locality.

Snow should not interrupt the MIUS services nor impair the MIUS buildings and equipment. All MIUS construction should withstand the structural load imposed by snow accumulated to depths common to the locality. Wind blown snow drifting or other accumulations should not impede the MIUS. Snow loading should be determined according to the local building code.

Evaluation See Evaluation: Criterion F.2.2.1. 
NBS-114A (REV. 7.73)

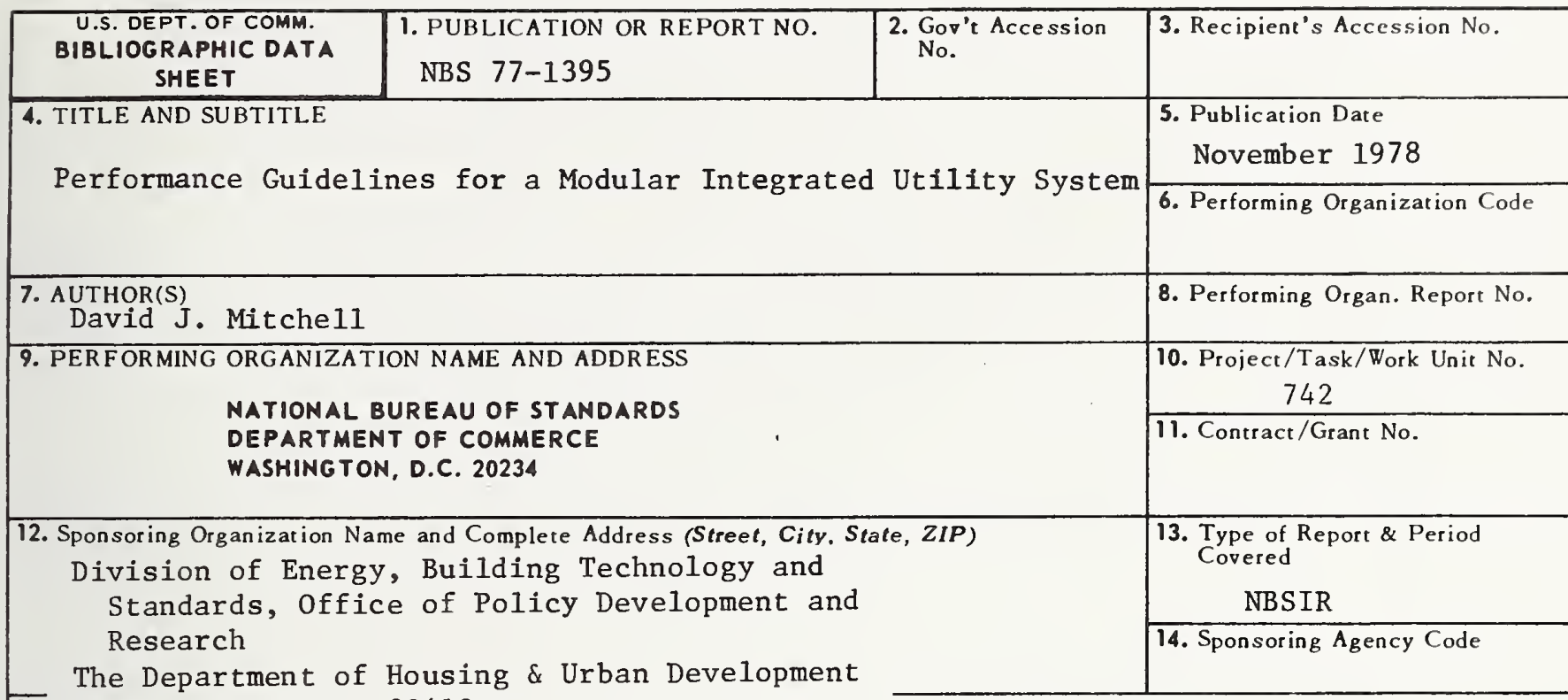

15. Washington, D.C. 20410

16. ABSTRACT (A 200-word or less factual summary of most significant in formation. If document includes a significant bibliography or literature survey, mention it here.)

Performance Guidelines for a Modular Integrated Utility System (MIUS) is an aid to construct conceptual, preliminary and final designs for a specific MIUS to be built in a particular geographic location.

This document defines generic performance of a MIUS serving a residential/commercial development. These performance requirements, criteria, and evaluations identify engineering parameters and other constraints associated with electrical service, thermal energy, solid waste management, potable water management, and wastewater management provided by a single, local, integrated source. There are also performance requirements, criteria, and evaluations for end-use considerations such as environmental impact, health, safety, and subjective acceptability. It is recognized that in view of the many possible combinations of MIUS designs, ownership, methods for implementation, local regulations, a MIUS implementor may wish to omit and/or greatly simplify many of the remaining performance requirements, cirteria and evaluations contained herein.

17. KEY WORDS (six to twelve entries; alphabetical order; capitalize only the first letter of the first key word unless a proper name; separated by semicolons)

Conservation, integrated utilities, performance guildelines, residential utilities, total energy, utilities.

\section{AVAILABILITY X Unlimited}

For Official Distribution. Do Not Release to NTIS

Order From Sup. of Doc., U.S. Government Printing Office Washington, D.C. 20402 , SD Cat. No. C13

Order From National Technical Information Service (NTIS) Springfield, Virginia 22151

\begin{tabular}{|l|l|}
\hline $\begin{array}{l}\text { 19. SECURITY CLASS } \\
\text { (THIS REPURT) }\end{array}$ & 21. NO. OF PAGES \\
UNCL ASSIFIED & 22. Price \\
\hline $\begin{array}{l}\text { 20. SECURITY CLASS } \\
\text { (THIS PAGE) } \\
\text { UNCLASSIFIED }\end{array}$ & \\
\hline
\end{tabular}





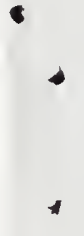


